\title{
APPLICATIONS OF VARIABLE ACOUSTICS
}

\author{
By
}

\section{Paria Esmaeil Khorasani}

(Bachelor of Engineering, Ryerson University, 2017)

\author{
A Major Research Project \\ Presented to Ryerson University \\ In Partial Fulfillment of the \\ Requirements for the Degree of \\ Master of Building Science (MBSc) \\ In the Graduate Program of Building Science \\ Toronto, Ontario, Canada, 2019 \\ (C) Paria Esmaeil Khorasani, 2019
}




\section{Author's Declaration}

I hereby declare that I am the sole author of this MRP. This is a true copy of the MRP, including any required final revisions.

I authorize Ryerson University to lend this MRP to other institutions or individuals for the purpose of scholarly research.

I further authorize Ryerson University to reproduce this MRP by photocopying or by other means, in total or in part, at the request of other institutions or individuals for the purpose of scholarly research.

I understand that my MRP may be made electronically available to the public. 
Applications of Variable Acoustics

Master of Building Science 2019

Paria Esmaeil Khorasani

Graduate Program of Building Science

Ryerson University

\begin{abstract}
This research investigates the use of variable acoustics and active acoustics system to improve the acoustics of the Paul H. Cocker Architecture Gallery at Ryerson University. These modifications can help the gallery become a multifunctional space in regards to acoustical characteristics of the room. Variation in acoustical response of a room requires use of different devices and material to change the reverberation and articulation time conveniently. Acoustical measurements were done in multiple locations at four multi-use auditoria with different variable acoustics features. These auditoria are Roy Thompson hall, Koerner Hall, Glenn Gould Studio and LiveLab at McMaster University. These case studies are used to better understand the acoustical responses of the auditoria with different configurations and use the data for the acoustical improvements of the Paul H. Cocker Architecture Gallery. After these evaluations were performed, results show that the acoustical poster board panels can be used to change the reverberation time of the Gallery based on the different uses.
\end{abstract}

Keyword: acoustics, variable acoustics, reverberation time, active acoustics system, passive acoustics systems 


\section{Acknowledgement}

This work would not have been possible without my professor and research advisor Dr. Ramani Ramakrishnan. I would like to thank Dr. Ramakrishnan for his support and dedication towards encouraging me to further my education in acoustics. My interest in the room acoustics led me to study the applications of variable acoustics. He always gave me reassurance and direction toward my goal. I truly enjoyed my time working on this project and learning more about room acoustics.

I would also like to thank my second advisor Dr. Mark Gorgolewski for his constructive feedback and guidance during the final stages of this major research project.

I would further like to thank my family, whose love and guidance are with me in whatever I pursue. My parents were always there to encourage me to follow my dreams. To my friends, for their understanding and support throughout this journey. This would not have been possible, without the help and support of all these wonderful people. 
Table of Contents

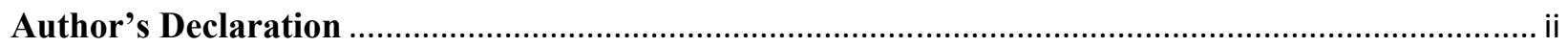

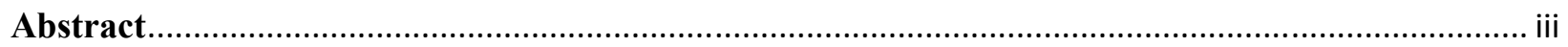

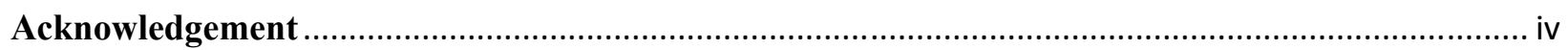

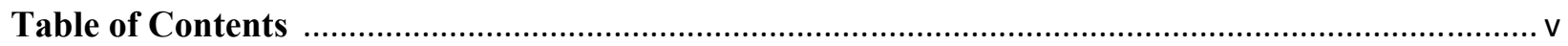

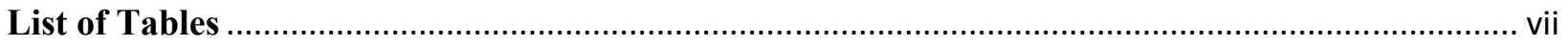

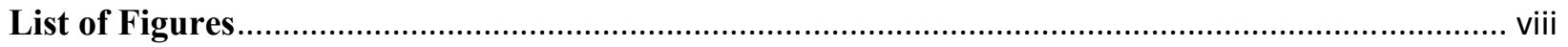

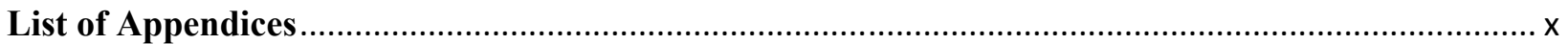

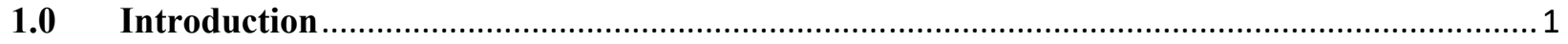

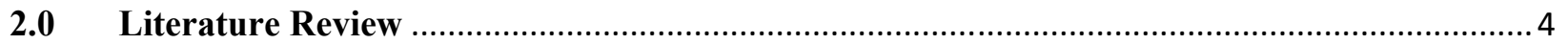

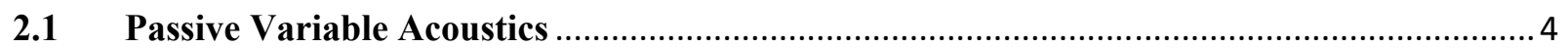

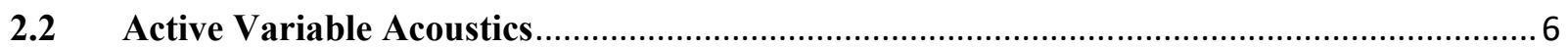

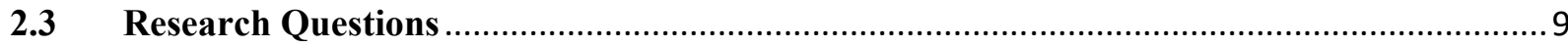

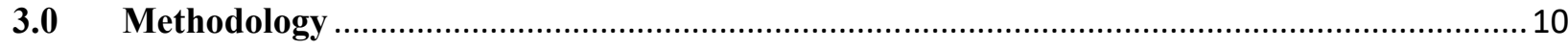

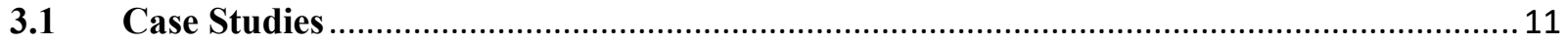

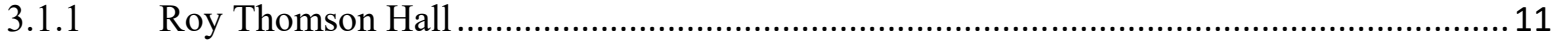

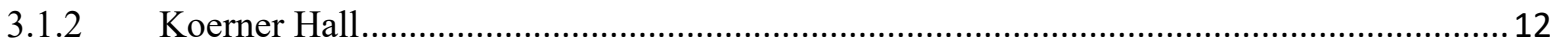

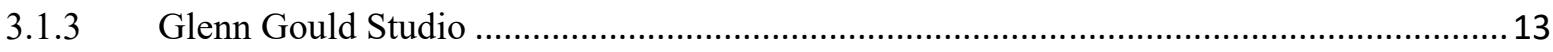

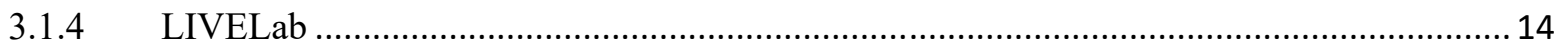

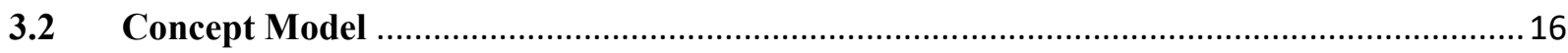

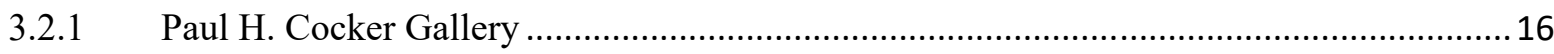

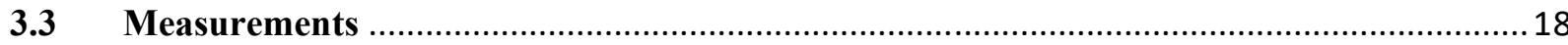

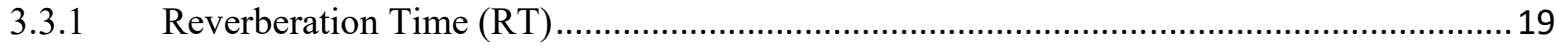

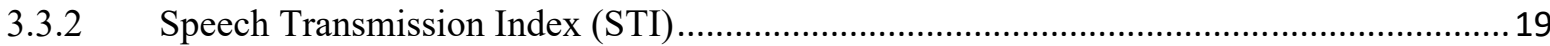

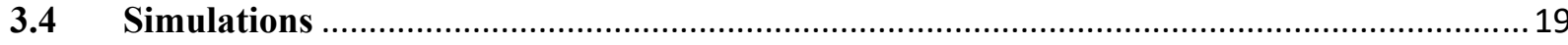

3.4.1 ODEON

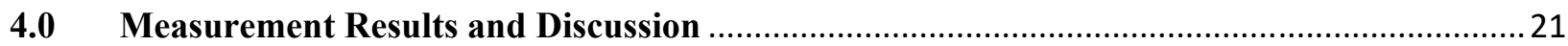

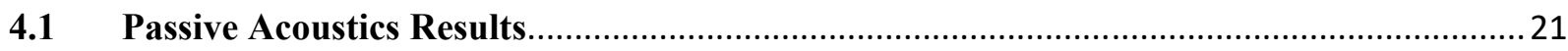

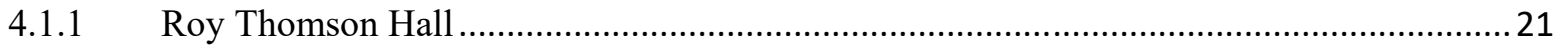

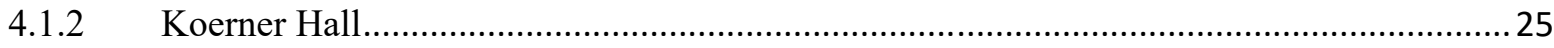

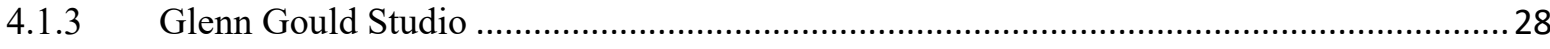

4.1.4 Summary of Passive Acoustics Results ....................................................................... 31 


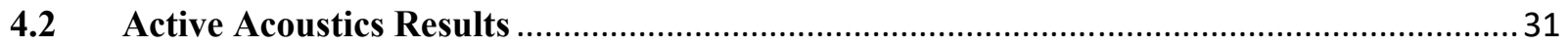

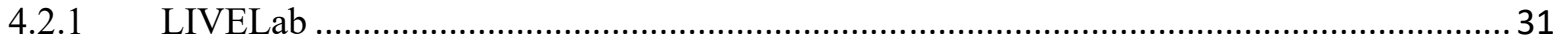

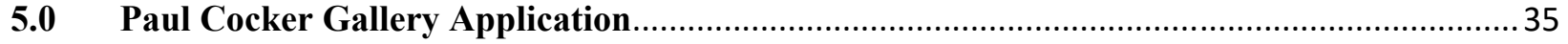

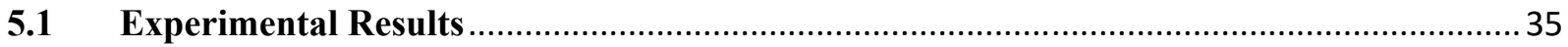

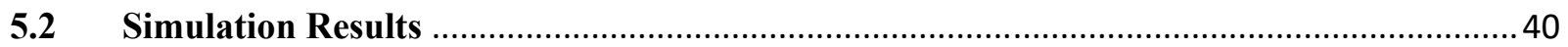

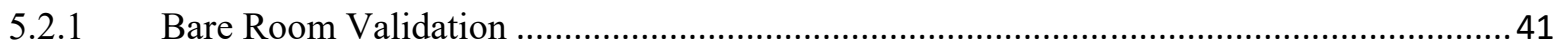

5.2.2 Room with Poster Board Panels..................................................................................... 42

5.2.3 Room with Acoustic Panels ............................................................................................ 45

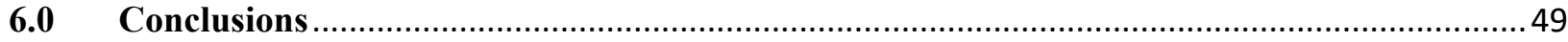

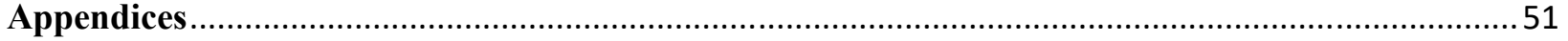

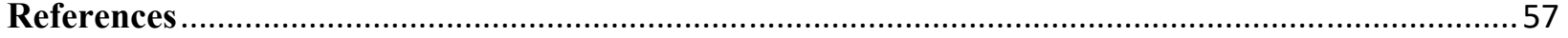




\section{List of Tables}

Table 1: Optimum Reverberation Time for Different Uses of the space (From Barron, [5]) ...................... 5

Table 2: Summary of Measurement Conditions in Roy Thomson Hall..................................................23

Table 3: Measurement Locations in Roy Thomson Hall ......................................................................... 23

Table 4: Summary of Measurement Conditions at Koerner Hall .......................................................... 26

Table 5: Measurement Locations at Koerner Hall ............................................................................. 26

Table 6: Summary of Measurement Conditions at Glenn Gould Studio .................................................29

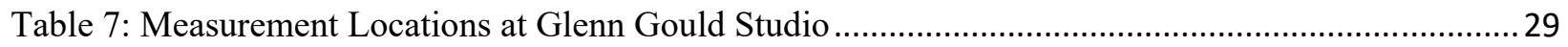

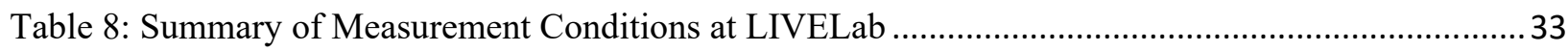

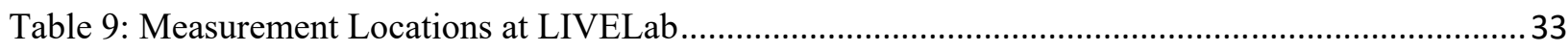

Table 10: Absorption Coefficient of the Poster Board Panels .................................................................35

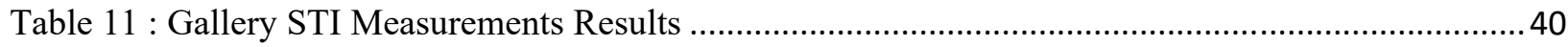

Table 12: Gallery Material Absorption Coefficients .............................................................................. 41

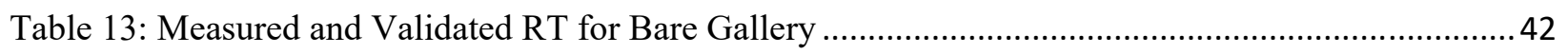

Table 14: Absorption Coefficient of the Poster Board Panels ..............................................................43

Table 15: Reverberation Time of Gallery Using 12 Panels .................................................................... 44

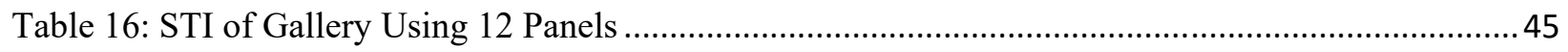

Table 17: Absorption Coefficient of the Acoustic Panels..................................................................... 45

Table 18: RT Results of Adding Acoustical Panels on Felt Part ......................................................... 46

Table 19: RT Results of Adding Acoustical Panels on Felt Part and Wall 1 ...........................................47

Table 20: RT Results of Adding Acoustical Panels on Felt Part and Wall 1 and 2 ................................ 48 


\section{List of Figures}

Figure 1: VRA System in Cornerstone Arts Center (Source: Online [10]) …....................................... 8

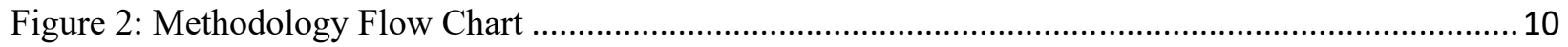

Figure 3: Picture of Roy Thomson Hall- View from the stage ............................................................. 12

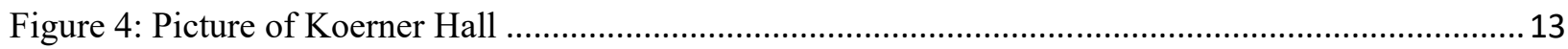

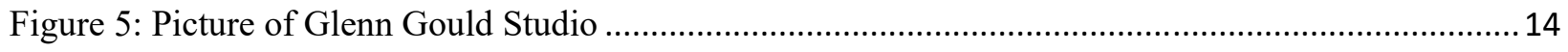

Figure 6: Picture of the LIVELab with Arrows Showing Hanging Microphones ................................... 15

Figure 7: Picture of LIVELab with Arrows Showing Speakers ............................................................... 15

Figure 8: Paul Cocker Gallery Glazing Doors and Interior ................................................................. 16

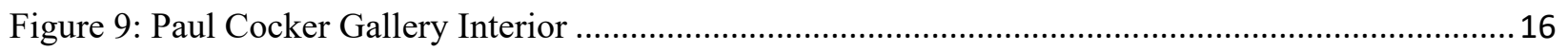

Figure 10: View of Poster Board Panels in Paul Cocker Gallery …...................................................... 17

Figure 11: Sine-Sweep Signal Measurement (Source: Online [15]).................................................... 18

Figure 12: Bruel \& Kjaer Speaker System.......................................................................................... 18

Figure 13: Picture of Main Canopy and Rear Canopy in Roy Thomson Hall ......................................... 21

Figure 14: Picture of Roy Thomson Hall with Drapes Down.............................................................. 22

Figure 15: Reverberation Time Results for Location 3 at Roy Thomson Hall ....................................... 24

Figure 16: Reverberation Time Results for Location 8 at Roy Thomson Hall ........................................ 24

Figure 17: Picture of Koerner Hall with Drapes closed at the Back .....................................................25

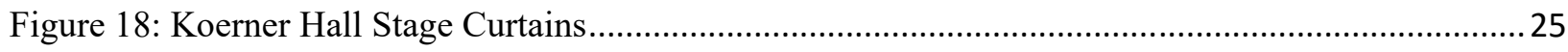

Figure 19: Reverberation Time Results for Location 3 at Koerner Hall ................................................27

Figure 20: Reverberation Time Results for Location 5 at Koerner Hall...............................................27

Figure 21: Picture of Stage Curtains Closed at Glenn Gould Studio .........................................................28

Figure 22: Picture of Side and Back Curtains open at Glenn Gould Studio ..........................................29

Figure 23: Reverberation Time Results for Location 3 at Glenn Gould Studio ...................................... 30

Figure 24: Reverberation Time Results for Location 5 at Glenn Gould Studio ...................................... 30

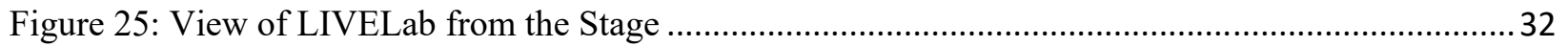

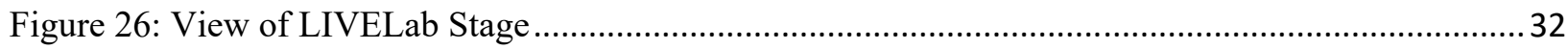

Figure 27: Reverberation Time Results for Location 2 at LIVELab .....................................................33

Figure 28: Reverberation Time Results for Location 3 at LIVELab ..................................................... 34

Figure 29: View of Poster Board Panels Used in Gallery...................................................................... 35

Figure 30: Paul Cocker Gallery Bare room Source and Receiver Locations.............................................36 


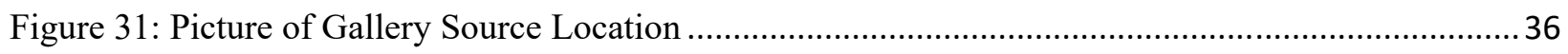

Figure 32: Paul H Cocker Gallery Two Poster Board Locations ................................................................. 37

Figure 33: Paul H Cocker Gallery Four Poster Board Locations.......................................................... 37

Figure 34: Paul H Cocker Gallery Six Poster Board Location .............................................................. 38

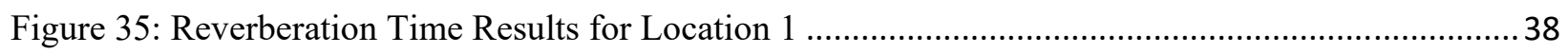

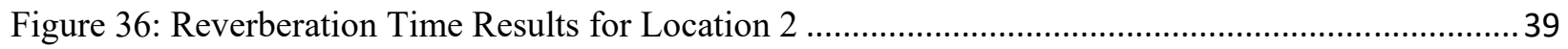

Figure 37: Reverberation Time Results for Location 3 ...................................................................... 39

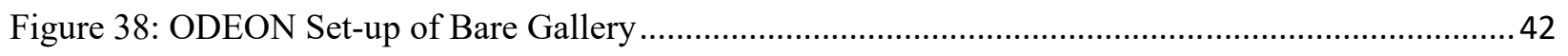

Figure 39: Gallery Modeled with Two Poster Board Panels ............................................................... 43

Figure 40: Reverberation Time Simulation Results............................................................................ 44

Figure 41: Location of Added Acoustic Panels on the Felt Part............................................................ 46

Figure 42: Location of Added Acoustic Panels on the Felt Part and Wall 1 ..........................................47

Figure 43: Location of Added Acoustic Panels on the Felt Part and Wall 1 and 2................................ 48 


\section{List of Appendices}

Appendix A: Roy Thomson Hall Measurement Results..................................................................... 51

Appendix B: Koerner Hall Measurement Results................................................................................ 54

Appendix C: Glenn Gould Studio Measurement Results .................................................................. 55

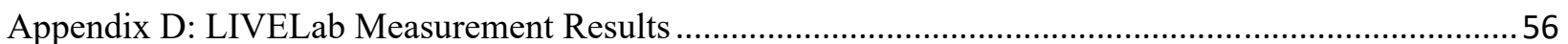




\subsection{Introduction}

Nowadays many Middle-sized cities with regional function have one cultural centre that is capable of holding all different kinds of events like lectures, concerts or symphonies and have multi-purpose uses. The different performances all have their specific acoustical requirements. The best approach to achieve the acoustical requirement of each kind of performance is to make the acoustic conditions variable so that they can be optimally adopted to each performance [1]. Therefore, the type of techniques applied to these spaces is referred to as "variable acoustics," where one can alter the acoustical environment by architectural (passive variable acoustics) or electronic means (active variable acoustics).

A Gallery space is located in the Ryerson University Architecture Building with the volume of $350 \mathrm{~m}^{3}$. The Gallery space is called Paul Cocker Gallery and it is considered a multipurpose room, which is used for different activities in addition of being a space used for exhibitions. This research focuses on how to achieve variable acoustics in the Gallery. The four major uses of the Gallery space are exhibitions, crit space, presentation with the use of speakers and LCD, and a small chamber music with 30 seats and 4 musicians.

Passive Variable acoustics can be achieved with movable curtains and ceilings with revolving panels [1]. Variation in the acoustical response of a room requires the use of devices by which the factors affecting articulation and reverberance can be adjusted quickly and conveniently. The primary methods of adjustment are changing early reflections by reorientation or relocation of reflecting surfaces, changing the volume of the space, and changing reverberant sound energy by the addition or removal of sound-absorbing materials. The reorientation or relocation of reflecting surfaces is very sensitive to fine adjustments. Changing the volume of the space and changing reverberant sound energy by the addition or removal of sound-absorbing materials, are 
relatively insensitive, requiring significant changes in volume or absorption. Combinations of these devices have been used successfully to achieve optimum conditions for uses ranging from symphonic music to speech [2].

The first systems for active variable acoustics based on controlled acoustic feedback was introduced in early 1960's. One of the well-known systems of this kind is Assisted Resonance System. It was used to lengthen the reverberation time over a limited frequency range. In addition, the Multi Channel Reverberation System was developed, which had large number of broadband channels in its early versions. The advantage of these systems was having user-friendly operation once the tuning has been done [1].

The quality, stability and flexibility of active acoustical systems for variable acoustics is highly improved in recent years and several systems are available in the market. Although there seems to be hesitations, even in today's technocratic society, to use electronics in relation with "serious" music, it is to be expected that, in a not too far future, variable electro-acoustics will be a standard facility in each multi-purpose hall. That is because researchers found that the passive variable acoustics in the halls often has limited acoustics variability and flexibility. In addition, the perceptual effect of passive variable acoustics like movable ceilings, reflectors and other boundary elements are believed to hardly be noticeable [1].

The current Major Research Project investigates the use of variable acoustics and active acoustics system to improve the acoustics of the Paul H. Cocker Architecture Gallery at Ryerson University. These modifications can help the gallery become a multifunctional space with appropriate acoustical characteristics. Variation in acoustical response of a room requires use of different devices and material to change the reverberation and articulation time conveniently. Acoustical measurements were conducted at four multi-use auditoria with different variable 
acoustics features. These auditoria are Roy Thompson hall, Koerner Hall, Glenn Gould Studio, and LIVElab at McMaster University. These case studies are used to better understand the acoustical responses of the auditoria with different configurations and use the data for the acoustical improvements of the Paul H. Cocker Gallery at Ryerson University. The four case studies were used in order to learn the effects of changing the materials in a room at different locations. These auditoria all have different sizes and different mechanism to change the acoustical characteristics of the room. Using the measurements that were conducted in these case studies, the most appropriate improvements that can be done in Gallery were tested in order to propose the most suitable ones in order to make Gallery a multipurpose room. 


\subsection{Literature Review}

Due to the high real estate costs, construction and maintenance costs, single purpose facilities for musical performances often are not feasible. Nowadays, it is becoming more normal to have flexibility of changing the use of the halls from speech to music to theater. This literature review focuses on the use of the passive variable acoustics and active variable acoustics in multipurpose rooms. Moreover, the results of the researches that were done regarding passive and active acoustics are discussed.

\subsection{Passive Variable Acoustics}

Adjustment methods for the passive variable acoustics includes changing early reflections by reorientation or relocation of reflecting surfaces, changing the volume of the space, and changing reverberant sound-energy by the addition or removal of sound-absorbing materials [2].

The main concern for designing multipurpose auditoria is that acoustical properties that make a space good for speech often can make it poor for music. For good speech intelligibility, there is little need for diffusion and room volumes and reverberation times should be low and the first reflections should be primarily from the ceiling [3]

However, for music, strong overhead reflections are not preferred and reflections that come from the side provide a desirable sense of enclosure while enhanced early reflections increase the sense of clarity. Added lateral reflections, which arrive early enough to enhance speech intelligibility, can also be advantageous for both music and speech. Consequently, rooms designed for unamplified music require longer reverberation times, higher volumes, lateral rather than overhead reflections, and high diffusion. Rooms designed for multipurpose uses require a thoughtful compromise between the needs of speech and music [3]. 
Marshal Long stated in his book of Architectural Acoustics that general traditional guidelines to apply for multipurpose rooms are the following [4]: a) The source should be elevated above he audience; b) If the music played is unamplified, singers and musicians should be aided by nearby reflective surfaces on their overhead and sides. Also, the singers and musicians should be close to each other; c) The audience space should be sloped and padded seating should be used to minimize the difference between the empty and occupied seats. d) Volume and absorption of the room should be able to be changed in order to have it according to the use of the room. e) Background noise levels should be limited to NC25 [4].

Table 1 shows the optimum reverberation time in seconds for different uses according to M. Barron and Jaffe [5][6]. This information was developed by acousticians based upon observations during performances and preferences from trained observers in a laboratory environment.

Table 1: Optimum Reverberation Time for Different Uses of the space (From Barron, [5])

\begin{tabular}{|c|c|}
\hline Use & Optimum reverberation time (S) \\
\hline Popular Music & $<1.0$ \\
\hline Drama Theatre & $0.7-1.0$ \\
\hline Opera and Ballet & $1.3-1.8$ \\
\hline Chamber Music & $1.4-1.8$ \\
\hline Orchestral Music & $1.8-2.2$ \\
\hline Lecture Hall & Less than 0.8 \\
\hline
\end{tabular}


Maria Cairoli studied architectural customized design for variable acoustics in a multipurpose auditorium [3]. Cairoli's main interest was to find architectural solutions to control variable acoustics within big range. Many configurations with different combinations of movable architectural elements have been recorded. The case study that she worked on was Calzedonia Auditorium, a shoe box of $10,200 \mathrm{~m}^{3}$.

It was found that inserting several movable elements such as curtains allows for each configuration to have acceptable acoustical characteristics across the frequency range from 125 to $4000 \mathrm{~Hz}$. In this auditorium, considering the removable seats made the variable absorption a more extravagant option for the design of architectural acoustics solution. When curtains are in hidden position, the auditorium ceiling is very absorbent at middle and high frequencies and the absorption variation referred to different pivoting panels positions are less effective, especially when the volume of the auditorium is not divided into two. It was concluded that customized Design of Acoustic and Architectural Solutions gives the opportunity to increase or reduce seamlessly sound absorbing properties of the auditorium surfaces within a present range [3].

\subsection{Active Variable Acoustics}

Adjustment methods for the active variable acoustics includes arranging microphones to detect relevant sound and the choice of processors and loudspeaker positions to direct it usefully back into the room to produce a desired set of acoustic parameters [7].

M. A. Poletti investigated the possibility of using active acoustics systems for control of a room acoustics and all the theoretical background behind it [7]. One of the earliest of this kind of system was Assisted Resonance system. It was designed to increase low-frequency reverberation time. Another approach was Multichannel Amplification of Reverberation (MCR) system, which 
used multiple wideband microphone-loudspeaker channels to reduce room absorption and increase reverberation time over a wide frequency. Another system that has regenerative component similar to the MCR system is Mayer sound Constellation system which is developed from Variable Room Acoustic (VRA) system. VRA unlike MCR includes a multichannel reverberator between the microphones and loudspeakers [7].

Roger Schwenke and Steve Ellison discussed the objective assessment of Active acoustics System performance and how active acoustics works in a room [8]. It was presented that the resulting warmth, clarity, and early decay time can be controlled independently from the late reverberation time, and that strength and binaural quality can be improved. Roger Schwenke and Steve Ellison also investigated the case for widely variable acoustics [9]. Different reverberation times and preferred ranges that are needed for different events that can happen in a room being investigated.

The research showed different case studies that use active acoustics systems. Some examples of the auditoria that use VRA algorithms and methodologies are the Nokia Concert Hall in Tallinn, Estonia, Cornerstone Arts Center at Colorado College, and University of California, San Diego Music Department's Experimental Theater [9]. Figure 1 shows a picture of Cornerstone Arts Center. 


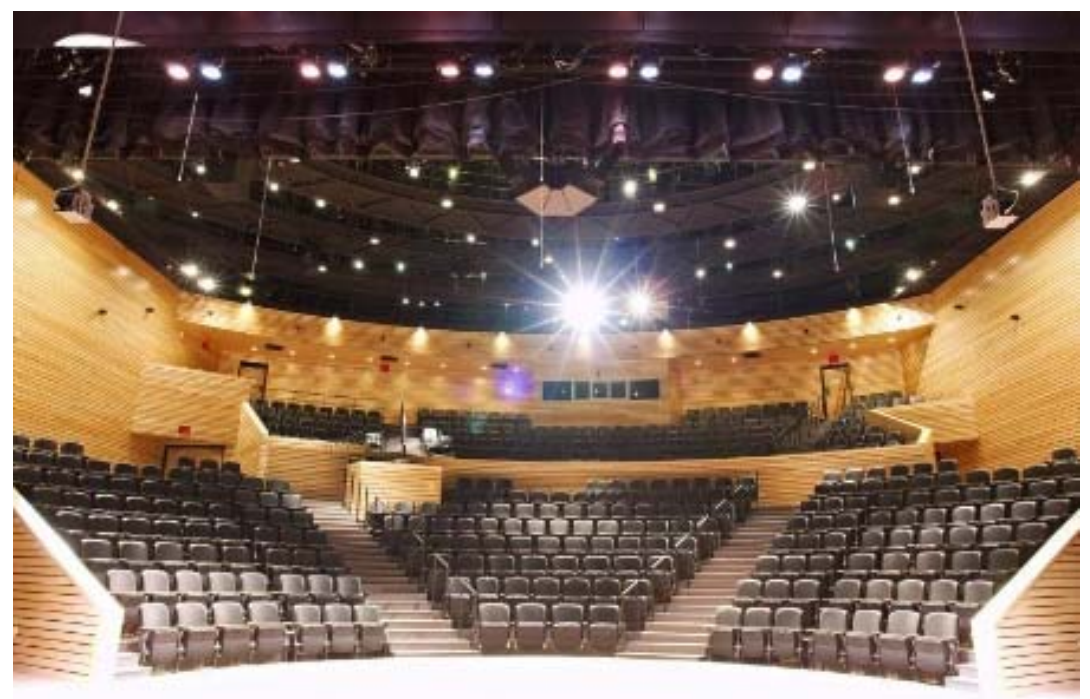

Figure 1: VRA System in Cornerstone Arts Center (Source: Online [10])

R. Schwenke and S. Ellison investigated the changes to reverberation time in different halls that use active acoustics [11]. The measurements were done in Logomo Hall in Turku, Finland. This hall has a massive seating stand that glides back and forth on compressed air cushion. This creates small, medium or large performance space. After the measurements were done, it was noted that the physical reverberation time reduces when the room size gets smaller. In the medium setting the reverberation time was measured to be changed from 1 second when the active acoustics is off to 1.5 seconds after turning the active acoustics on. The reverberation time could be further changed to be as long as 2.5 seconds for $1000 \mathrm{~Hz}$ frequency [11].

R. Schwenke Also investigated the active acoustics system installed at TUI operettenhaus in Hamburg [12]. The system used in this venue is Constellation system which uses the Variable Room Acoustic System (VRAS) algorithm invented and patented by Mark Poletti. Without the active noise control the reverberation time in this venue is measured to be 0.25 seconds for $1000 \mathrm{~Hz}$ frequency. By using the active control system, it was shown that the reverberation time can be increased to 1.25 seconds and as long as 3.7 seconds [12]. 


\subsection{Research Questions}

The literature review showed that the multifunctional spaces need to have variation in the acoustical response of the space. These variations require the use of devices by which the factors affecting articulation and reverberance can be adjusted quickly and conveniently. The devices that were used were the poster board panels filled with Rockwool.

The poster board panels have a hard backing with Rockwool fill and a perforated facing. These panels are on wheels and easily movable and the option of adding different number of panel boards is available. The placement of the poster boards with Rockwool infill is one of the aspects of the passive acoustics. Paul Cocker Gallery is used as a multipurpose space; therefore, the approach to improve the space lead to the following research questions:

1. How to modify the Gallery for different uses?

2. How would the poster board panels' placements effect the acoustic response of the Gallery?

3. Can we include active acoustic control for different performance of the Gallery?

4. Can some of the passive and/or active acoustic controls be used for other spaces at Ryerson? 


\subsection{Methodology}

The main focus of this investigation is the application of variable acoustics to the multipurpose functions of Paul H. Cocker Gallery. The impact of different passive variable acoustics on the acoustical response of an enclosed room were studied. This investigation includes both experimental and computer simulation methods. The measurements were done to look at the acoustical performance in four existing spaces that use variable acoustics. These spaces were Roy Thomson Hall, Koerner Hall, Glenn Gould Studio, and LIVELab in McMaster University. Afterwards, experiments were conducted within Paul Cocker Gallery, and finally computer simulations is done for Gallery. An overview of the methodology can be found in Figure 2.

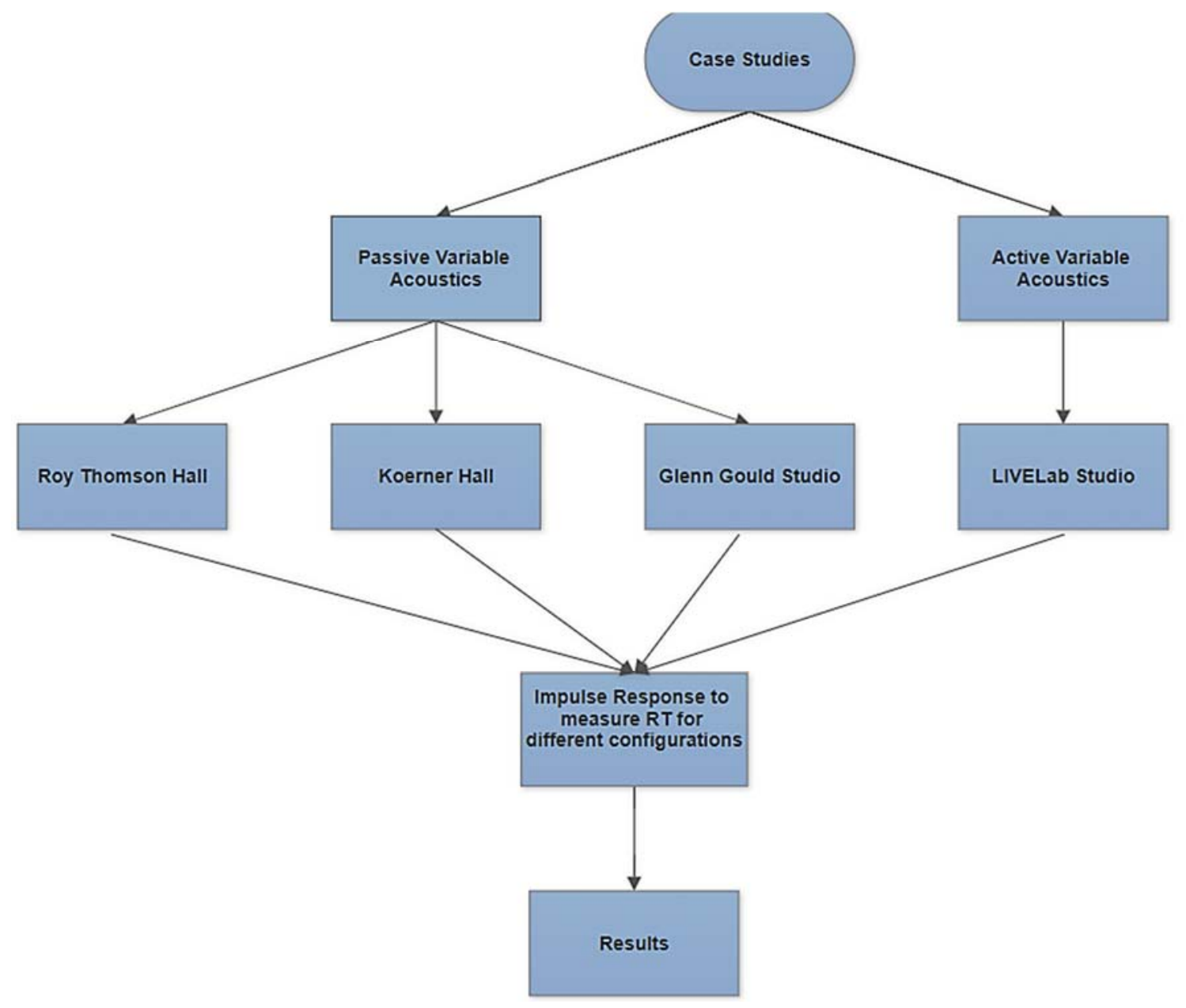

Figure 2a: Methodology Flow Chart 


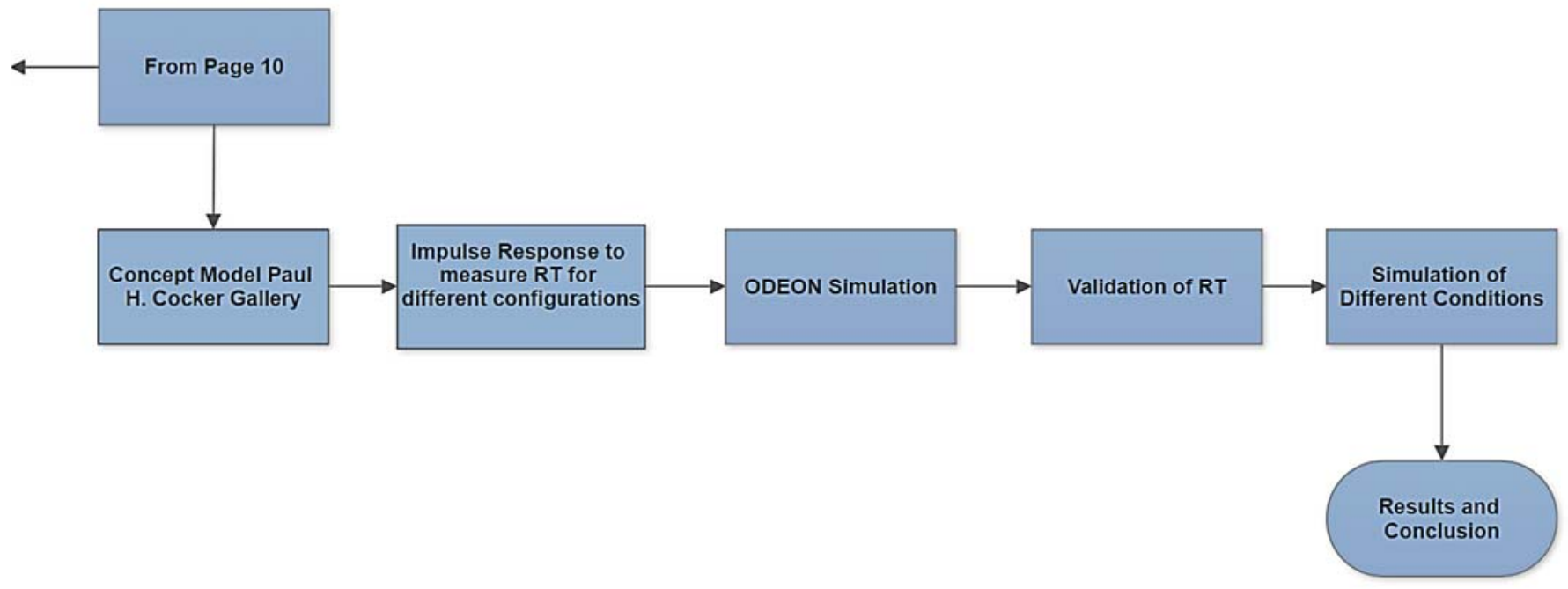

Figure 2b: Methodology Flow Chart

\subsection{Case Studies}

Acoustical measurements were conducted at four multi-use auditoria. Three out of four used passive variable acoustics to control the acoustics of the room. Those three auditoria are Roy Thomson Hall, Koerner Hall, and Glenn Gould Studio. Also, one out of four case studies used active variable acoustics to control the acoustics of the room. The name of the auditoria that used active acoustics is LIVELab Studio.

\subsubsection{Roy Thomson Hall}

Roy Thomson Hall is a concert hall located in downtown Toronto's entertainment district. The hall has the capacity of 2,630 people and volume of $24,070 \mathrm{~m}^{3}$. This hall opened in 1982 and under went major renovation in 2002. This multi-use hall is used for symphony orchestra, choir, 
movie theater, concerts, shows and social events. The finish on the floor is resonant Canadian maple. The variable acoustics in his hall are the two large adjustable wooden canopies, one in the centre of the hall and the other over the stage. In addition, the sound absorbing banners on the walls are retractable. Figure 3 shows a picture of Roy Thomson Hall.

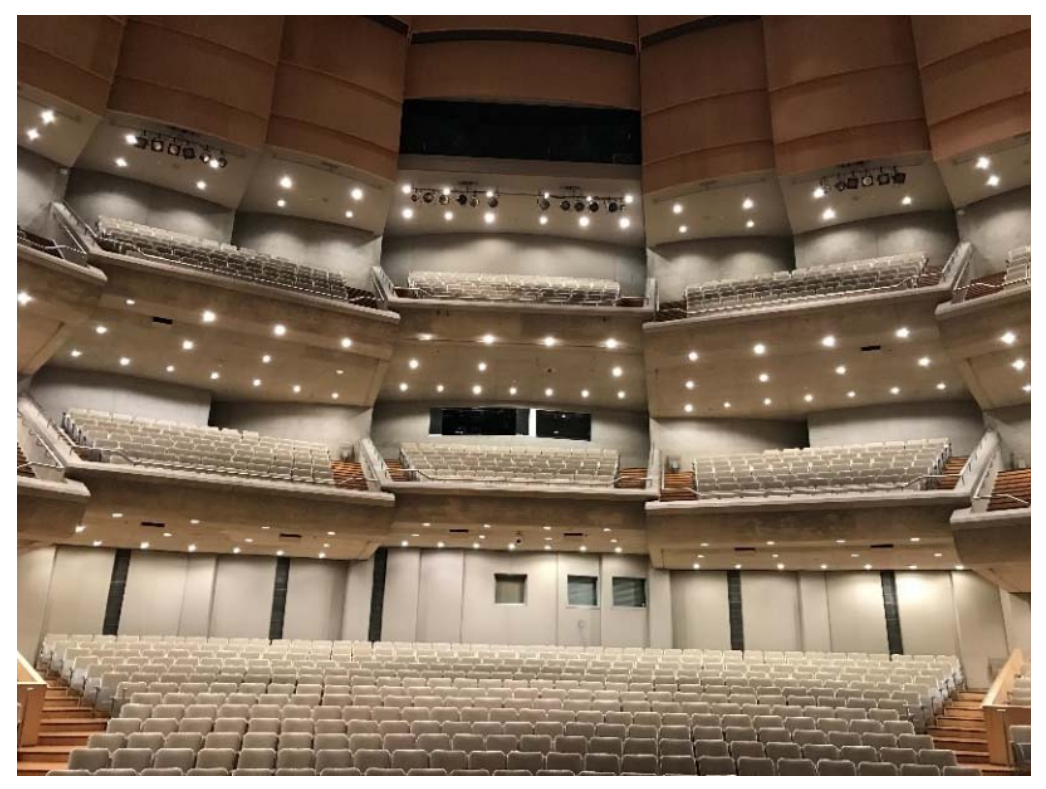

Figure 3: Picture of Roy Thomson Hall- View from the stage

\subsubsection{Koerner Hall}

Koerner hall is located in The Royal conservatory of music in downtown Toronto. This hall is known for its acoustics, which seats 1,135 guests and hosts wide range of musical acts. The variable acoustics in this hall is the adjustable heavy valour used in the back of stage and also curtains on the walls which can adjusted to go up and down in order to reveal the hard reflective surfaces. The finishes of this hall wood as well. Figure 4 shows a picture of Koerner Hall. 


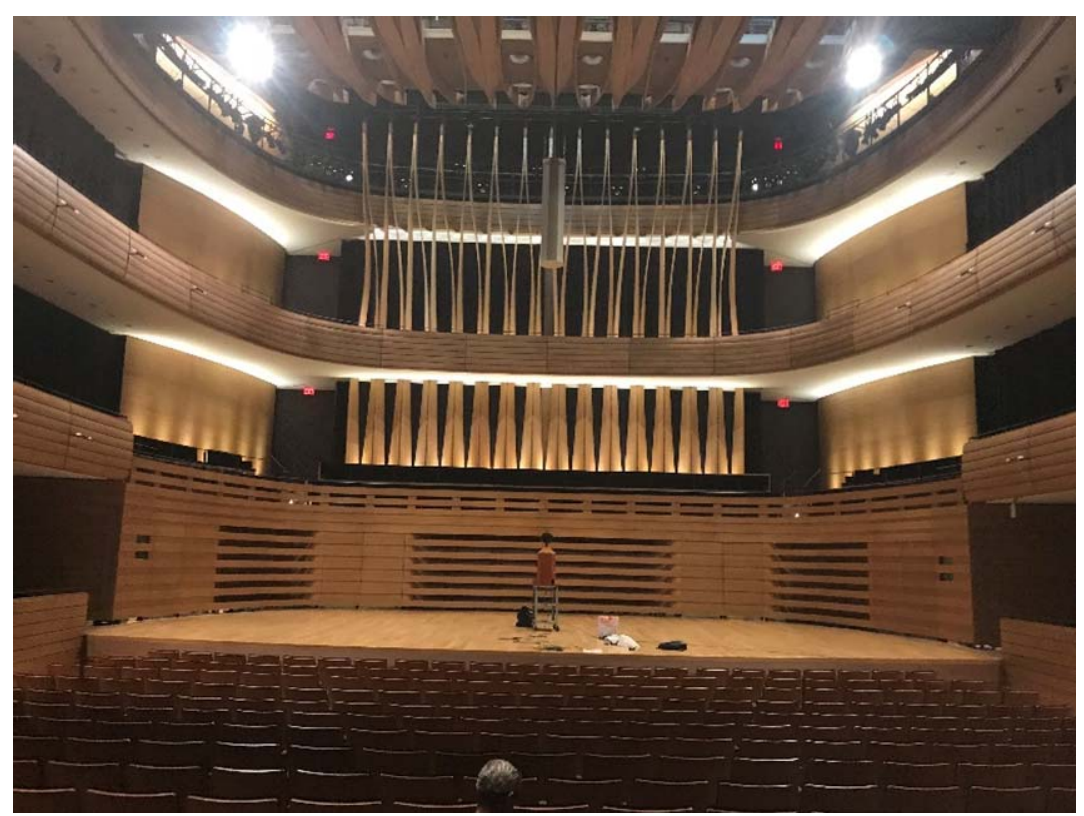

Figure 4: Picture of Koerner Hall

\subsubsection{Glenn Gould Studio}

Glenn Gould Studio is located in downtown Toronto is a radio concert hall inside the CBC Production building. Glen Gould is one of the premier concert venues in Toronto and many classical, jazz, and world musical concerts were performed inside this venue. This auditorium has the seating capacity of 340 guests offering and intimate environment for variety of performances. Glen Gould studio is built in the classic shoebox design constructed of oak and maple flooring, plaster walls, and polylaminate materials. The surfaces have been fabricated to allow for maximum dispersion of sound. Some absorptive elements have been integrated into the walls to bring the reverberation time of the room to 1.6 seconds. This state of the art facility offers incredible sound isolation of NC-15. The variable acoustics used in this auditorium are the absorptive drapes that are used at the back of the stage and on the side walls. Figure 5 shows a picture of Glenn Gould Studio. 


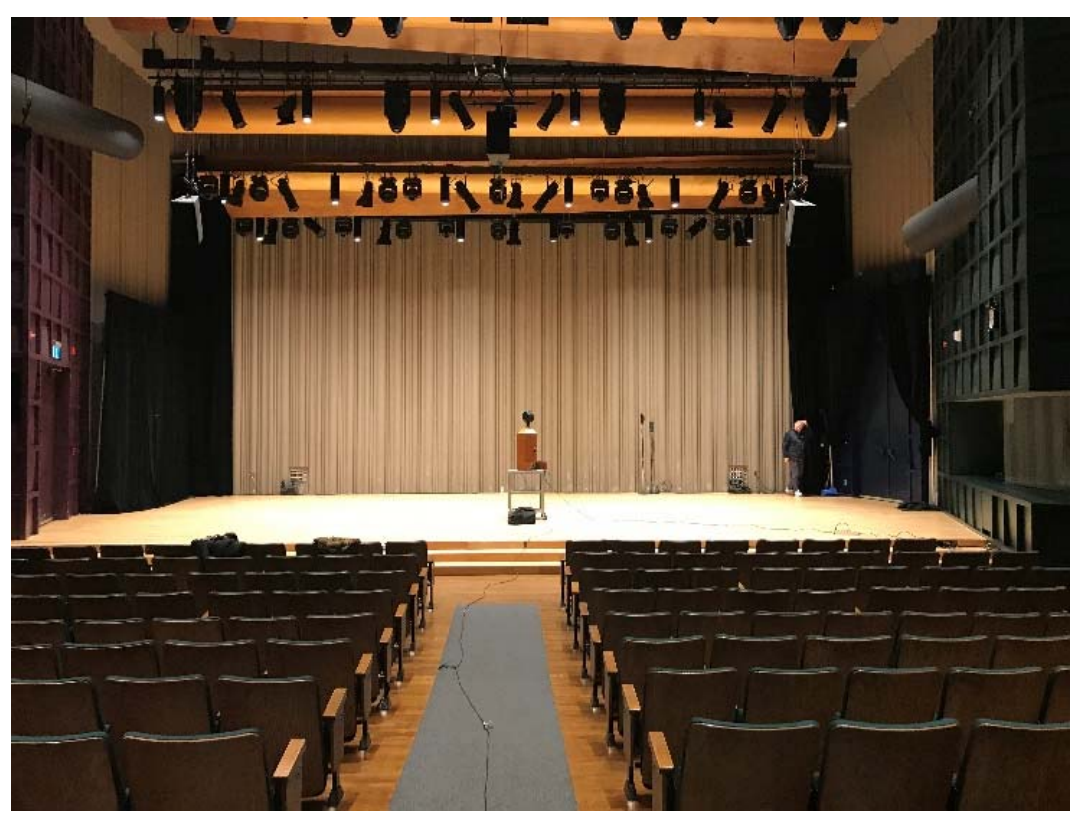

Figure 5: Picture of Glenn Gould Studio

\subsubsection{LIVELab}

The LIVE (Large Interactive Virtual Environment) Lab is a unique 106-seat Research Performance Hall designed to investigate the experience of music, dance, multimedia presentations, and human interaction. This auditorium is located at McMaster University in Hamilton, Ontario. The active variable acoustics used in this room is the Mayer Sound Constellation system. The Active Acoustics system allows for changing the reverberation time digitally to recreate any type of environment, such as a cathedral, concert hall, or classroom. The LIVELab is constructed with the strictest noise isolation standards, which can allow for studying the impacts of levels of background noise that is down to NC10. There are 72 speakers and 20 hanging microphones in this venue. The cost of installing the active acoustics in this room was around one million dollars. Figure 6 and Figure 7 show the picture of LIVELab and point out the speakers and microphones. 


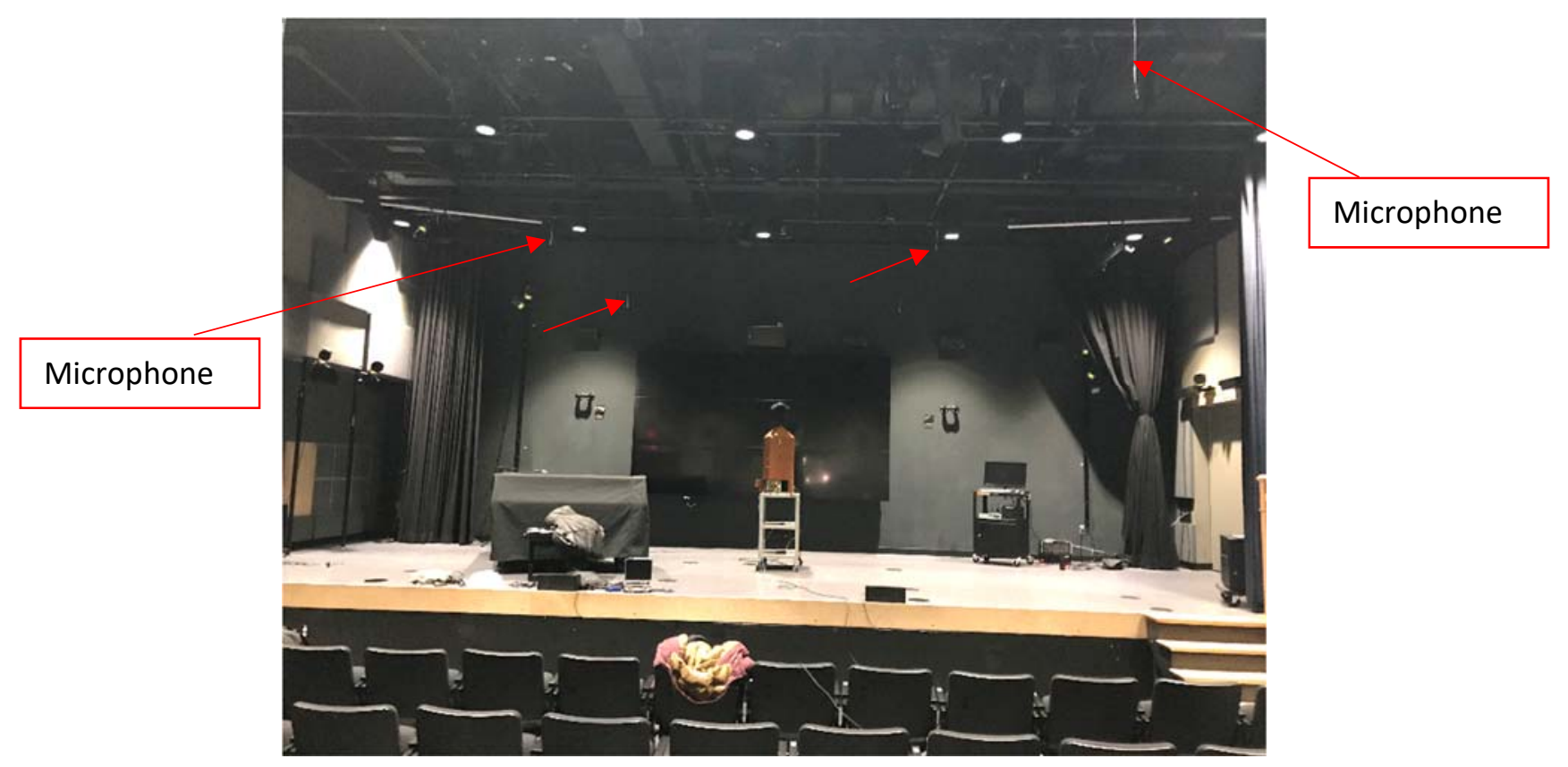

Figure 6: Picture of the LIVELab with Arrows Showing Hanging Microphones

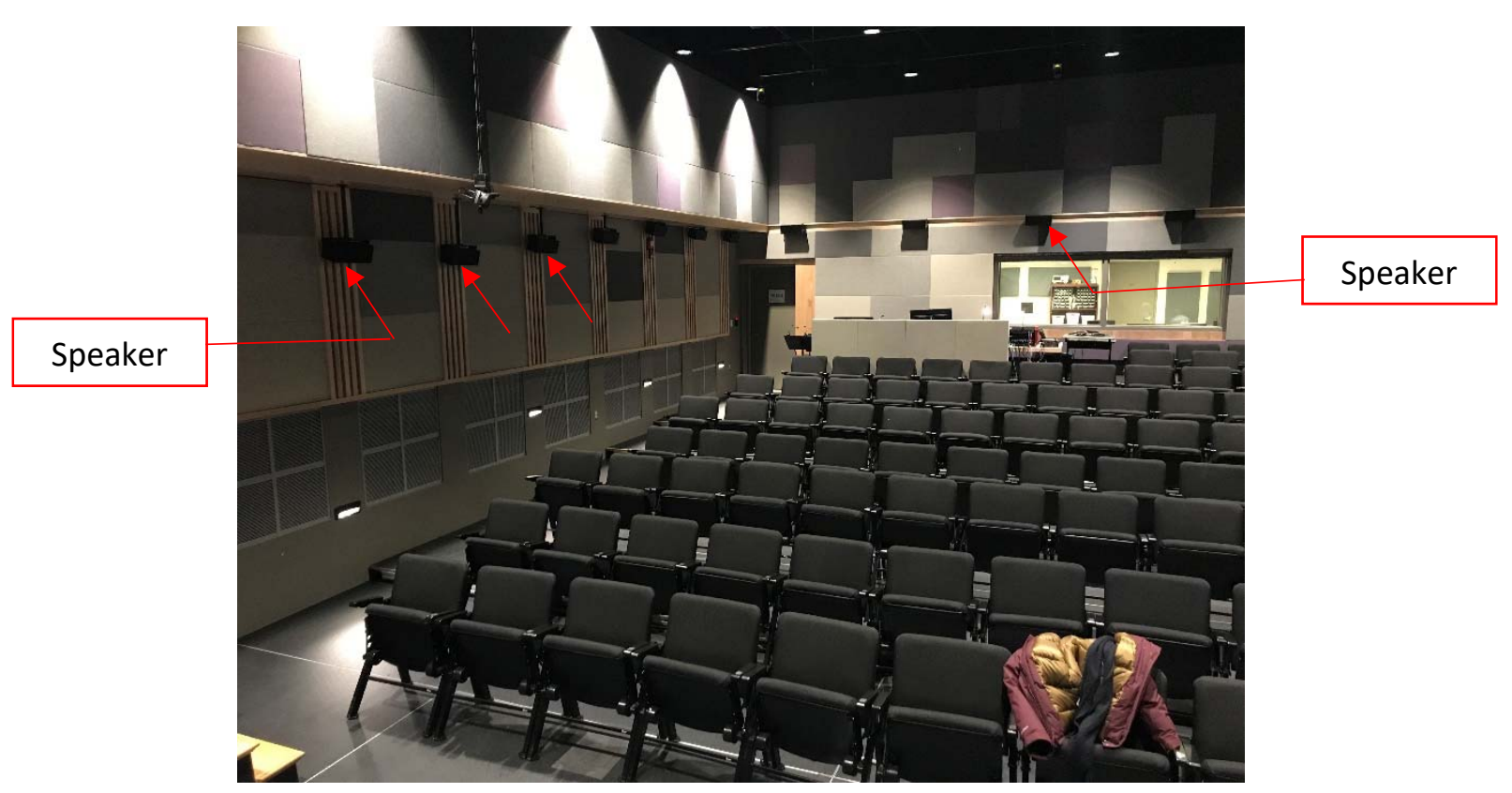

Figure 7: Picture of LIVELab with Arrows Showing Speakers 


\subsection{Concept Model}

The concept model is Paul H. cocker Gallery which is located at the Ryerson University Architecture building, which is located at downtown Toronto, Ontario. This is a multipurpose room and is used to investigate the applications of variable acoustics.

\subsubsection{Paul H. Cocker Gallery}

Paul H. Cocker Gallery is currently used for exhibitions, presentations, receptions and other gathering events. The room is made of mostly gypsum board walls and curtain wall glazing. The ceiling is made up of painted concrete and a concrete column is located inside the room as well. The space has the volume of $350 \mathrm{~m}^{3}$. Figure 8 and

Figure 9 show the interior of the Paul H Cocker Gallery.

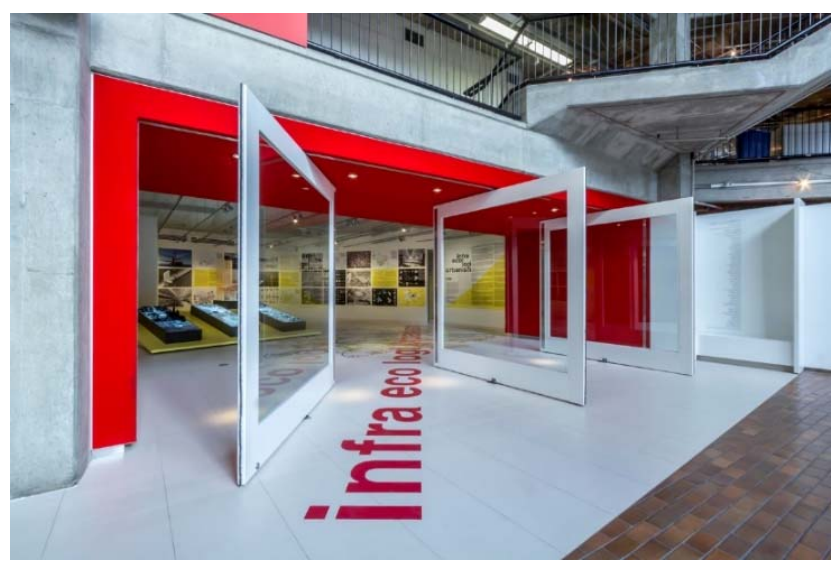

Figure 8: Paul Cocker Gallery Glazing Doors and Interior

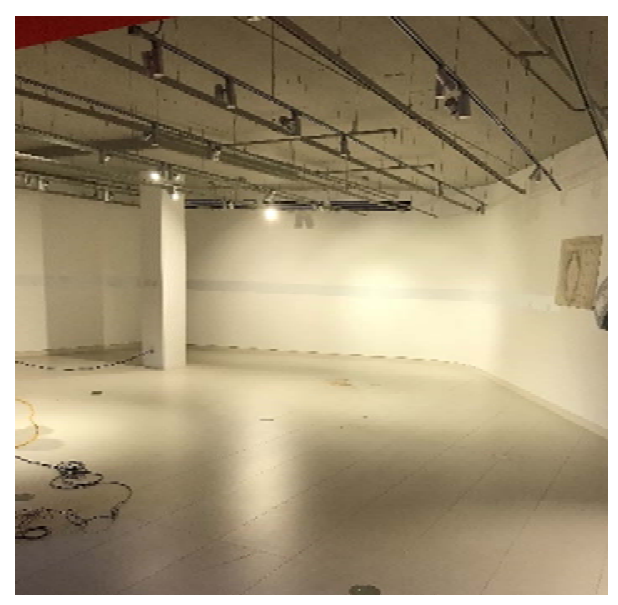

Figure 9: Paul Cocker Gallery Interior 
In order to change the acoustic response of the room, poster boards with high absorption values were used. These poster board panels are made of perforated sheet, Rockwool, and wood backing. Rockwool is a stone wool insulation and is one of the best porous absorption materials available. Thus, these boards are able to change the acoustical characteristics of the room. Figure 10 shows two of the acoustic boards in gallery. Measurements in Gallery were for the bare room, and with two acoustic or four acoustic or six acoustic poster board panels. The measurements were done in order to be used for the validation of ODEON simulation of bare room and also to compare different configurations of panels and its effect on the acoustical parameters of the room.

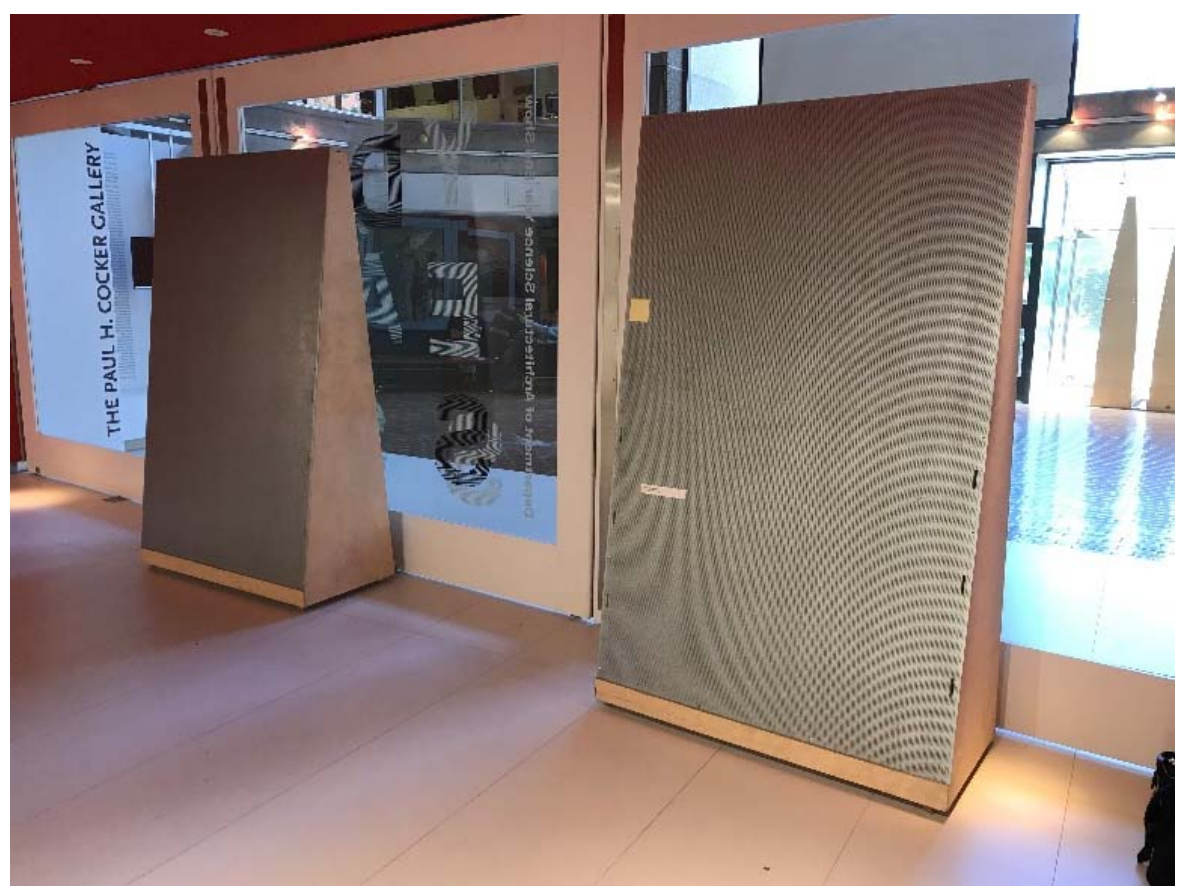

Figure 10: View of Poster Board Panels in Paul Cocker Gallery 


\subsection{Measurements}

Measurement of the impulse response in 8-octave bands of the room were done using sinesweep signal. The impulse response contains a wealth of information about an acoustical system including reverberation time and speech transmission index. The signals were 8 to 10 seconds long and occurred at each octave band Frequency. Approximately five spots in each case study with different modifications of the room were measured. Figure 11 shows how sign sweep signal measurement is done using sound source, microphone and a computer. Figure 12 shows the sound source used for the measurements, which is a Bruel \& Kjaer Speaker system.

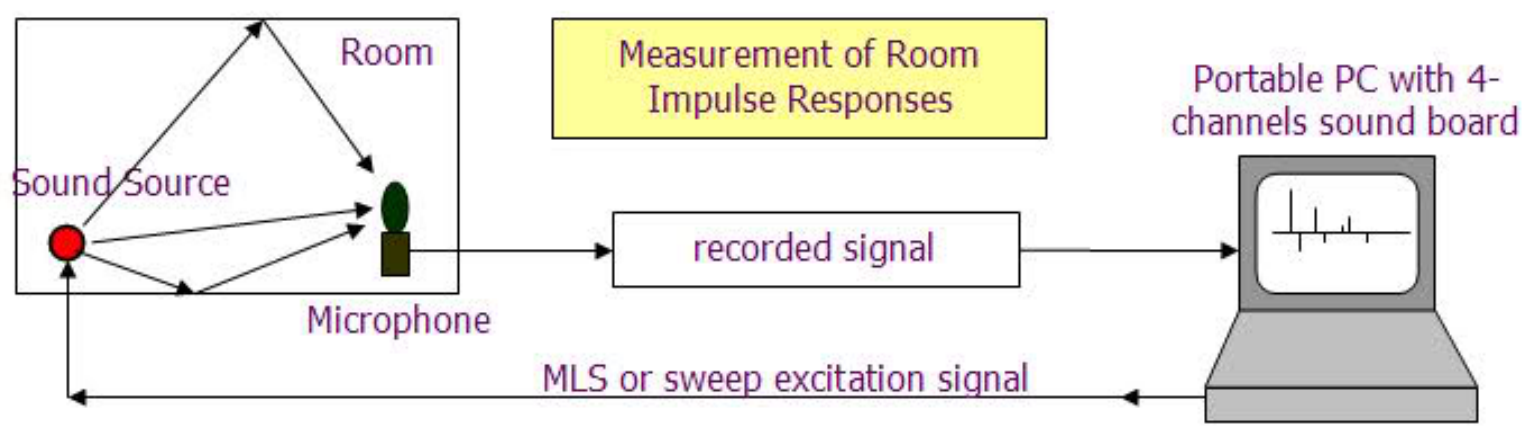

Figure 11: Sine-Sweep Signal Measurement (Source: Online [15])

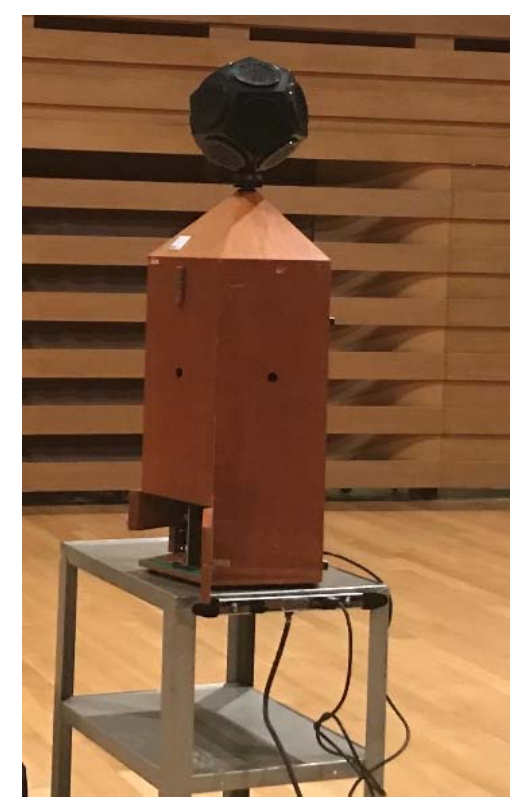

Figure 12: Bruel \& Kjaer Speaker System 
The measurements were conducted to evaluate a few acoustic metrics. The most important acoustic metrics that were evaluated from the impulse response measurements are the following:

\subsubsection{Reverberation Time (RT)}

Reverberance is the best known metric of subjective room acoustic aspect. When a room creates too much reverberance, speech loses intelligibility. For music, reverberance can add an attractive fullness to the sound. The reverberation time, $\mathrm{RT}_{30}$ is the traditional objective measure of reverberance and is the time taken for the sound to decay by $30 \mathrm{~dB}$ after the sound source is turned off [13].

\subsubsection{Speech Transmission Index (STI)}

The Speech Transmission Index is an objective, physical measure of speech transmission quality. The STI can be from 0.0 to 1.0 index and it indicates degree of speech intelligibility. When a perfect intelligible speech is transferred through a channel with STI of 1.0, the speech remains intelligible perfectly. When the STI value approaches the zero, more information through speech is lost. The STI between 0.75 and 1.0 indicates an excellent intelligibility rating [14].

\subsection{Simulations}

\subsubsection{ODEON}

Analysis and simulation of the results is done using ODEON. ODEON is a computer software that is used to simulate and measure interior acoustical parameters of a room. The software uses image source along with modified ray tracing to simulate the acoustical response of the room. A 3D model of the room is used in the program and materials are assigned to each layer. In addition, the room geometrics and material properties can be entered to program. ODEON is the most suitable software for this research project due its ease of use and having a library with 
wide variety of materials to be used. The Paul H. Cocker Gallery is modeled and simulated using ODEON in order to validate the bare room simulation and also to simulate the best configurations of variable acoustics for each different use of the Gallery [16]. 


\subsection{Measurement Results and Discussion}

The experimental measurements were conducted at the Roy Thomson Hall, Koerner Hall, Glenn Gould Studio, LIVElab and finally the Gallery. The measurements using the sine-sweep acoustics signal were done in order to compare the Reverberation Time and Speech Transmission Index for the different locations in different conditions.

\subsection{Passive Acoustics Results}

Among all the case studies that the measurements were done, three of them used passive variable acoustics to control the acoustics of the room. Those measurements and results are discussed bellow.

\subsubsection{Roy Thomson Hall}

The measurements at Roy Thomson Hall were done in eight different locations of the hall with two on the stage and the rest at the audience area. The speaker was placed at the centre of the stage. The measurements were done using four different mixed configurations of the canopy and drapes. Figure 13 shows the main canopy and the rear canopy and Figure 14 shows the back drapes being down.

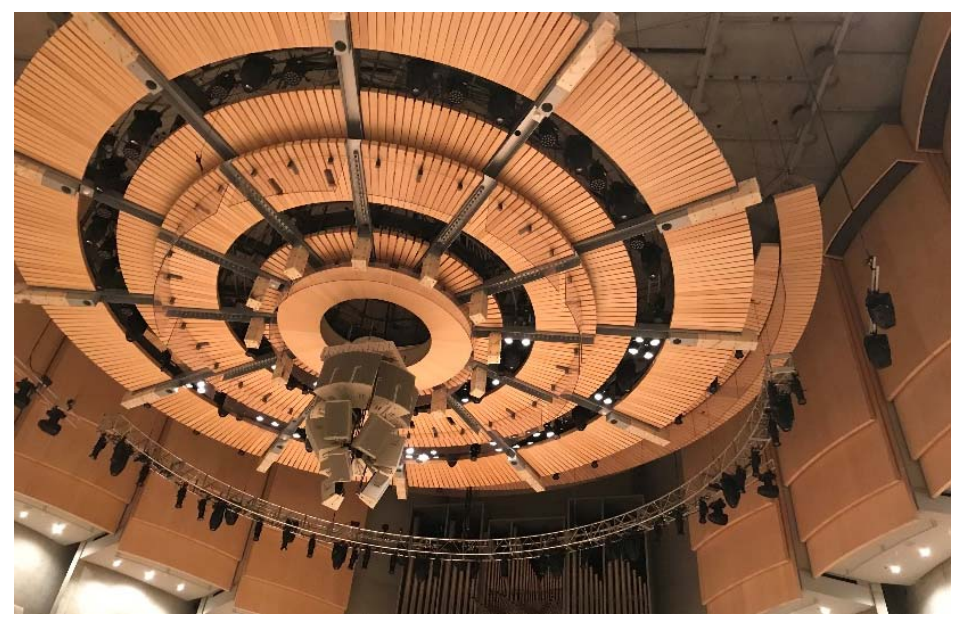

Figure 13: Picture of Main Canopy and Rear Canopy in Roy Thomson Hall 


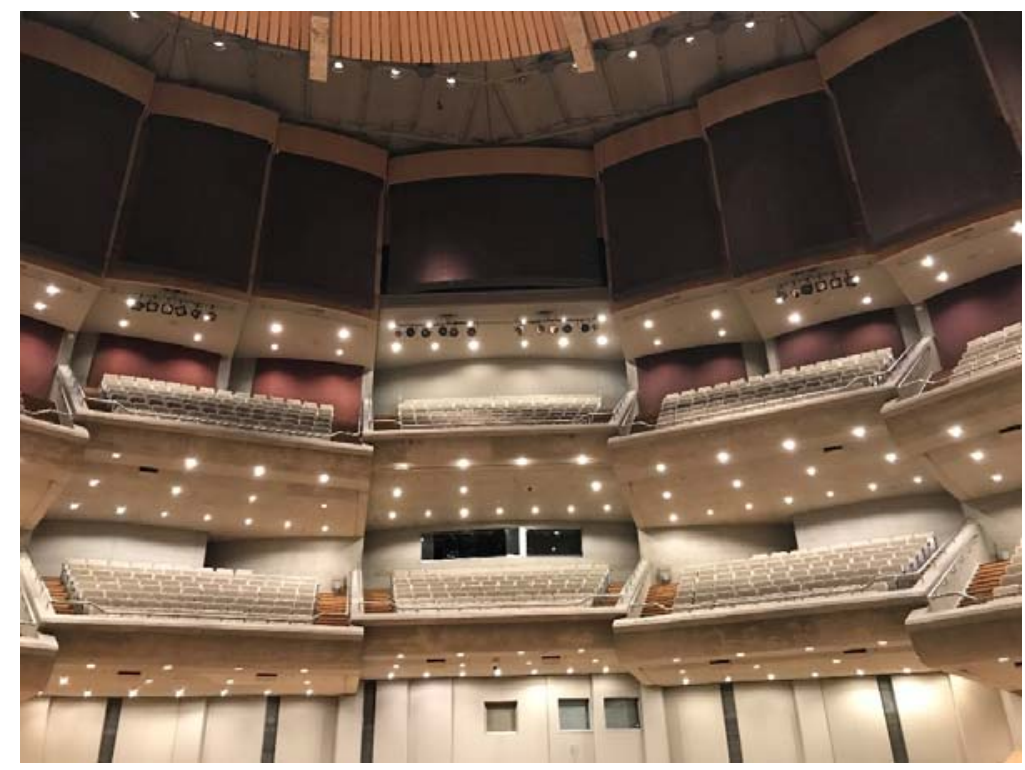

Figure 14: Picture of Roy Thomson Hall with Drapes Down

The measurements were done in four different conditions of the hall. Condition 1 was the Normal Symphony Condition. All drapes, banners and panels were up and bulkheads were open. Main canopy was at 38 feet and rear canopy was at 41 feet. In Condition 2 All drapes, banners and panels were up and bulkheads were open. Main canopy was at 38 feet and rear canopy was at 48 feet. In Condition 3, All banners and panels were in. Bulkheads were covered with banners (soft goods) and balcony level was covered with panels (A material with insulation to absorb sound in between). Also, main canopy was at 38 feet and rear canopy was at 48 feet. Finally, in Condition 4, all banners and panels were in. Bulkheads were covered with banners (soft goods) and balcony level was covered with panels. Main canopy was at 38 feet and rear canopy was at 41 feet. Table 2 shows a summary of different conditions that were measured in Roy Thomson hall. 
Table 2: Summary of Measurement Conditions in Roy Thomson Hall

\begin{tabular}{|c|c|c|c|c|}
\hline & $\begin{array}{c}\text { Drapes, Banners } \\
\text { and Panels }\end{array}$ & Bulkheads & $\begin{array}{c}\text { Main } \\
\text { Canopy }\end{array}$ & Rear Canopy \\
\hline $\begin{array}{c}\text { Condition 1 } \\
\text { (Normal Symphony } \\
\text { Condition) }\end{array}$ & $\mathrm{Up}$ & Open & $38 \mathrm{ft}$ & $41 \mathrm{ft}$ \\
\hline Condition 2 & $\mathrm{Up}$ & Open & $38 \mathrm{ft}$ & $48 \mathrm{ft}$ \\
\hline Condition 3 & Down & Close & $38 \mathrm{ft}$ & $48 \mathrm{ft}$ \\
\hline Condition 4 & Down & Close & $38 \mathrm{ft}$ & $41 \mathrm{ft}$ \\
\hline
\end{tabular}

The measurements in Roy Thomson Hall were done in eight different locations. Table 3 shows the seat number of locations that the measurements were done. The row numbers in Roy Thomson Hall start from the front to be A.

Table 3: Measurement Locations in Roy Thomson Hall

\begin{tabular}{|c|c|}
\hline Location 1 \& 2 & Stage \\
\hline Location 3 & B33 \\
\hline Location 4 & B33 \\
\hline Location 5 & B25 \\
\hline Location 6 & K 36 \\
\hline Location 7 & K43 \\
\hline Location 8 & K27 \\
\hline
\end{tabular}

After the measurements were done for eight different locations in the hall, the results for reverberation time for different locations and conditions are plotted. Figure 15 shows the results for location 3 which is a seating in front of the hall and Figure 16 shows the results for location 8 which is the seating in the back. The rest of the results including the locations at the stage are shown in Appendix A which shows the impact of bulkheads and canopy on the reverberation times. 


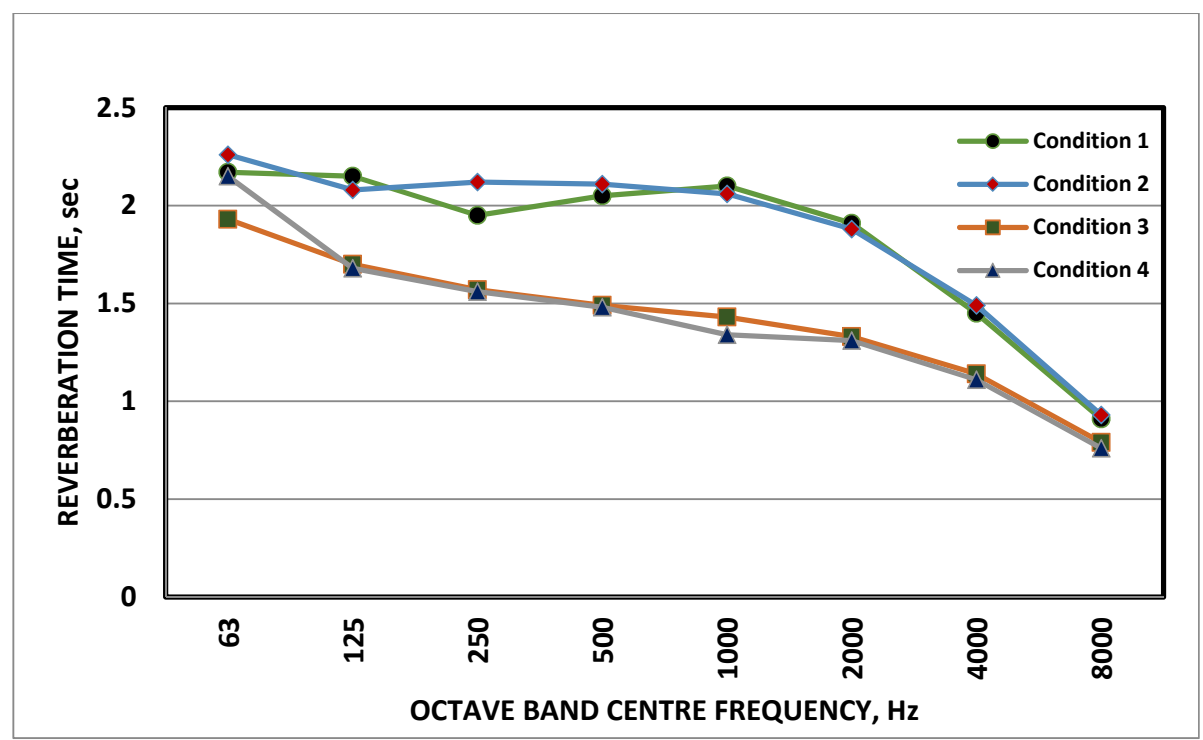

Figure 15: Reverberation Time Results for Location 3 at Roy Thomson Hall

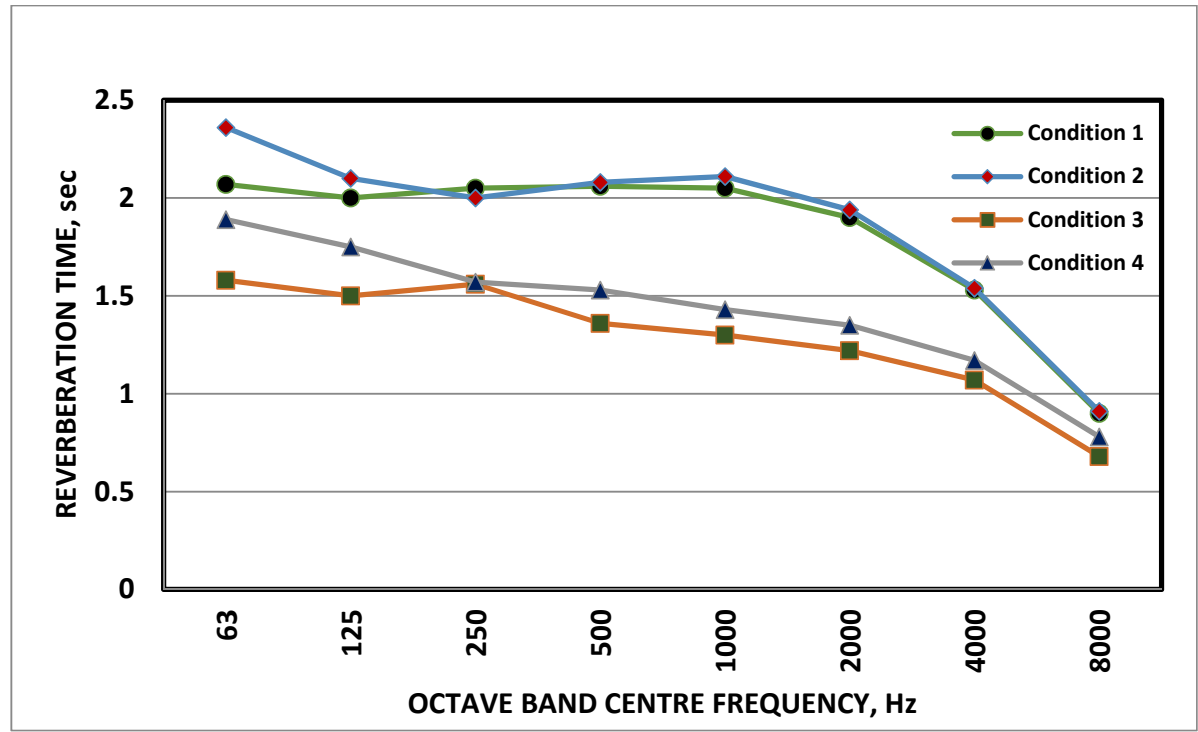

Figure 16: Reverberation Time Results for Location 8 at Roy Thomson Hall

The results show that Canopy's location does not have a lot of impact on the reverberation time. However, closing the bulkheads and putting down all the drapes panels and banners, decreased the reverberation time significantly due to these material being highly absorptive. Condition 1 and 2 both are proven to be good settings to be used for orchestral music. In addition, condition 3 and 4 are suitable to be used for opera and ballet performance or chamber music. 


\subsubsection{Koerner Hall}

The measurements were done in five different locations of the hall with two on the stage and rest at the audience area. The speaker was placed at the middle of the stage. The measurements were done using three different configurations of the drapes. Figure 17 shows the drapes in the back of the hall being in the closed position and Figure 18 shows the stage curtains which are heavy valour.

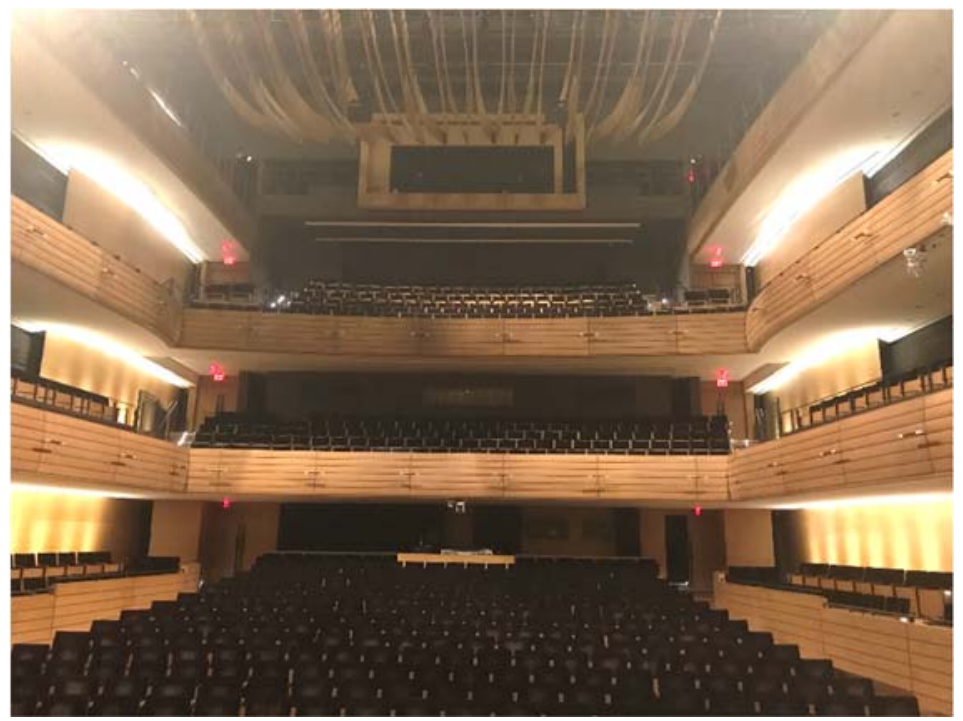

Figure 17: Picture of Koerner Hall with Drapes closed at the Back

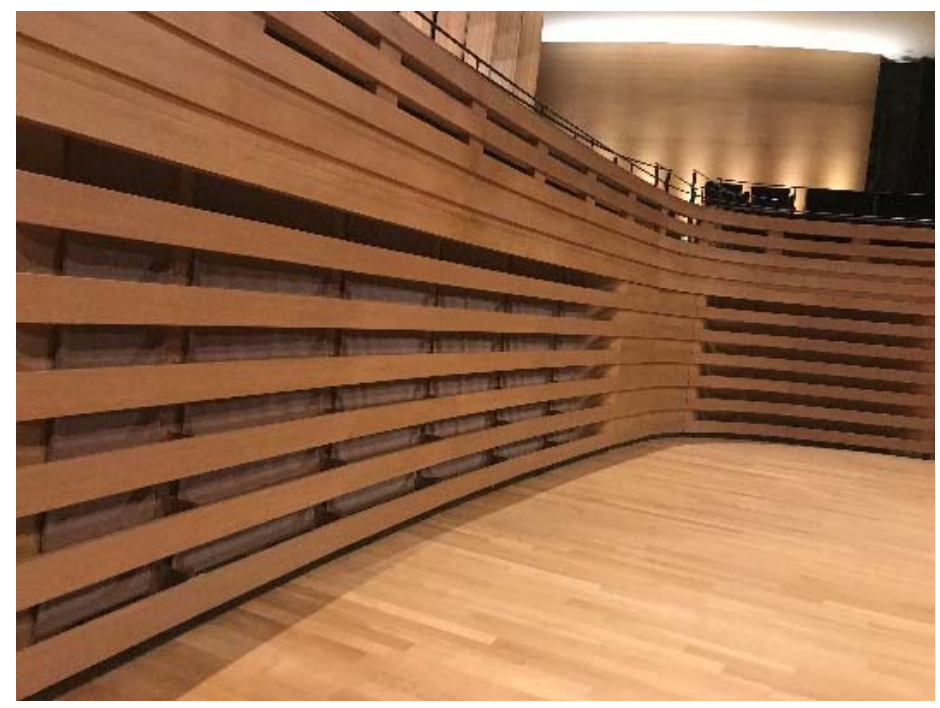

Figure 18: Koerner Hall Stage Curtains 
The Conditions and locations of the measurement in the Koerner Hall are summarized in Table 4 and Table 5 .

\section{Table 4: Summary of Measurement Conditions at Koerner Hall}

\begin{tabular}{|c|c|c|}
\hline & $\begin{array}{c}\text { Side \& back } \\
\text { Curtains }\end{array}$ & $\begin{array}{c}\text { Stage } \\
\text { Curtains }\end{array}$ \\
\hline Condition 1 & Down & Down \\
\hline Condition 2 & Down & Up \\
\hline Condition 3 & Up & Up \\
\hline
\end{tabular}

Table 5: Measurement Locations at Koerner Hall

\begin{tabular}{|c|c|}
\hline Location 1 \& 2 & Stage \\
\hline Location 3 & CC14 \\
\hline Location 4 & F14 \\
\hline Location 5 & M10 \\
\hline
\end{tabular}

After the measurements were done for five different locations in the hall, the results for reverberation time for different locations and conditions are plotted. Figure 19 shows the results for location 3 which is a seating in front of the hall and Figure $\mathbf{2 0}$ shows the results for location 5 which is the seating in the back. The rest of the results for other locations including the stage can be found in Appendix B which shows the impact of stage curtains on the reverberation times. 


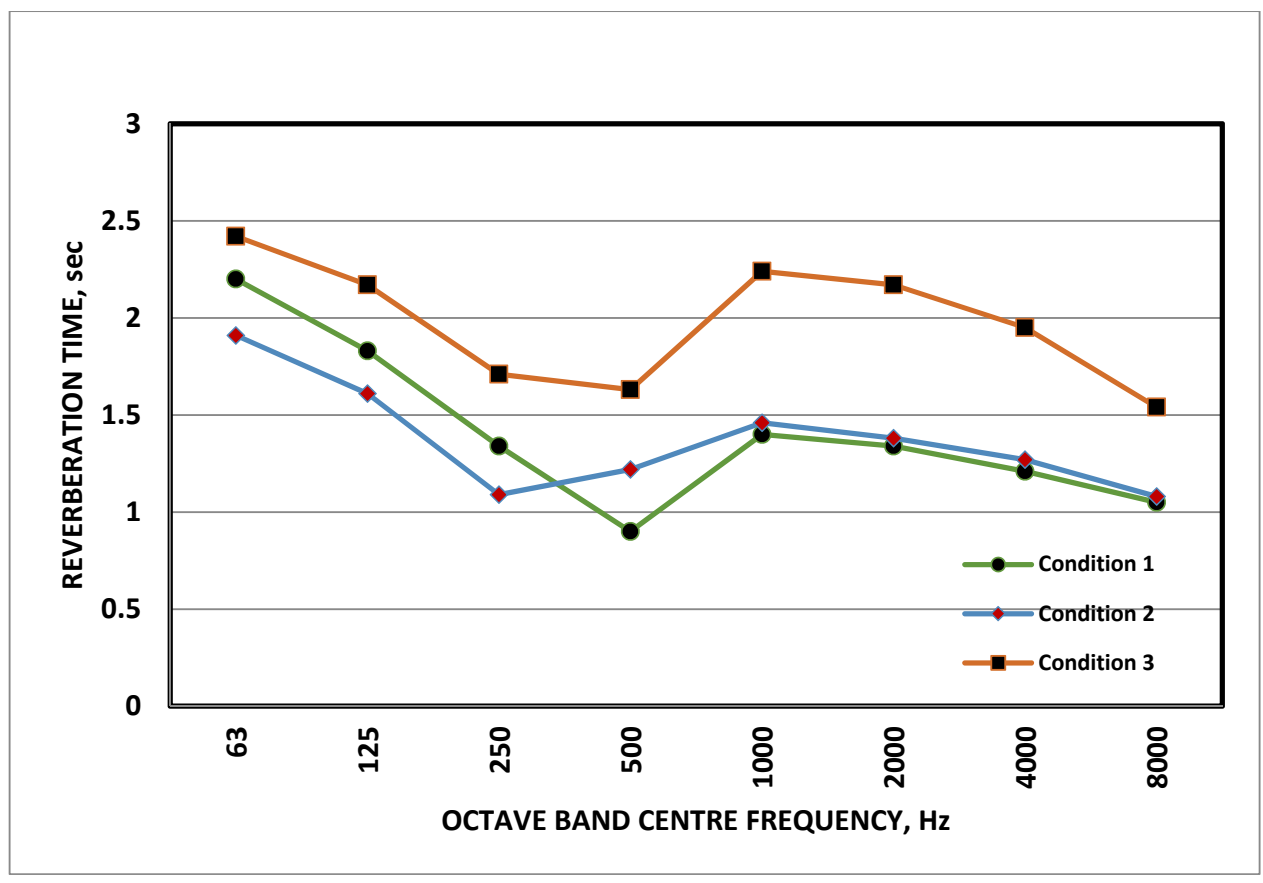

Figure 19: Reverberation Time Results for Location 3 at Koerner Hall

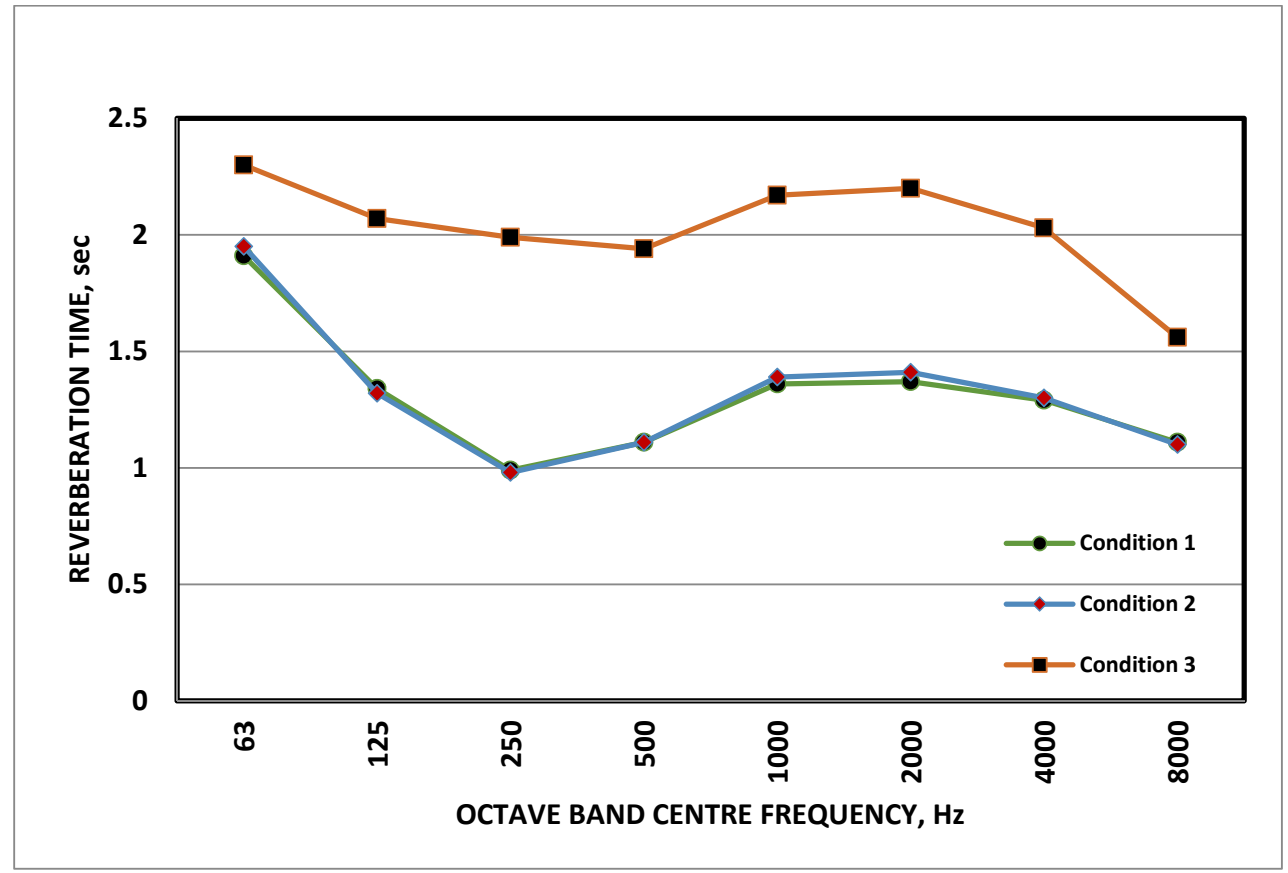

Figure 20: Reverberation Time Results for Location 5 at Koerner Hall 
The measurement results show that the curtains at the back of the stage do not have a lot of impact on the reverberation time. The closer the receiver to the stage the greater the impact of the curtains at the back of the stage to the reverberation time. However, when the side and back curtains are down, the reverberation time decreased significantly. Condition 1 can be used as a concert hall and condition 2 and 3 are good fit for opera and ballet.

\subsubsection{Glenn Gould Studio}

The measurements were done in five different locations of the hall with two of on the stage and rest at the audience area. The speaker was placed at the middle of the stage. The measurements were done using three different configurations of the drapes. Figure 21 and Figure 22 show the curtains of the stage, side and back used in Glenn Gould Studio.

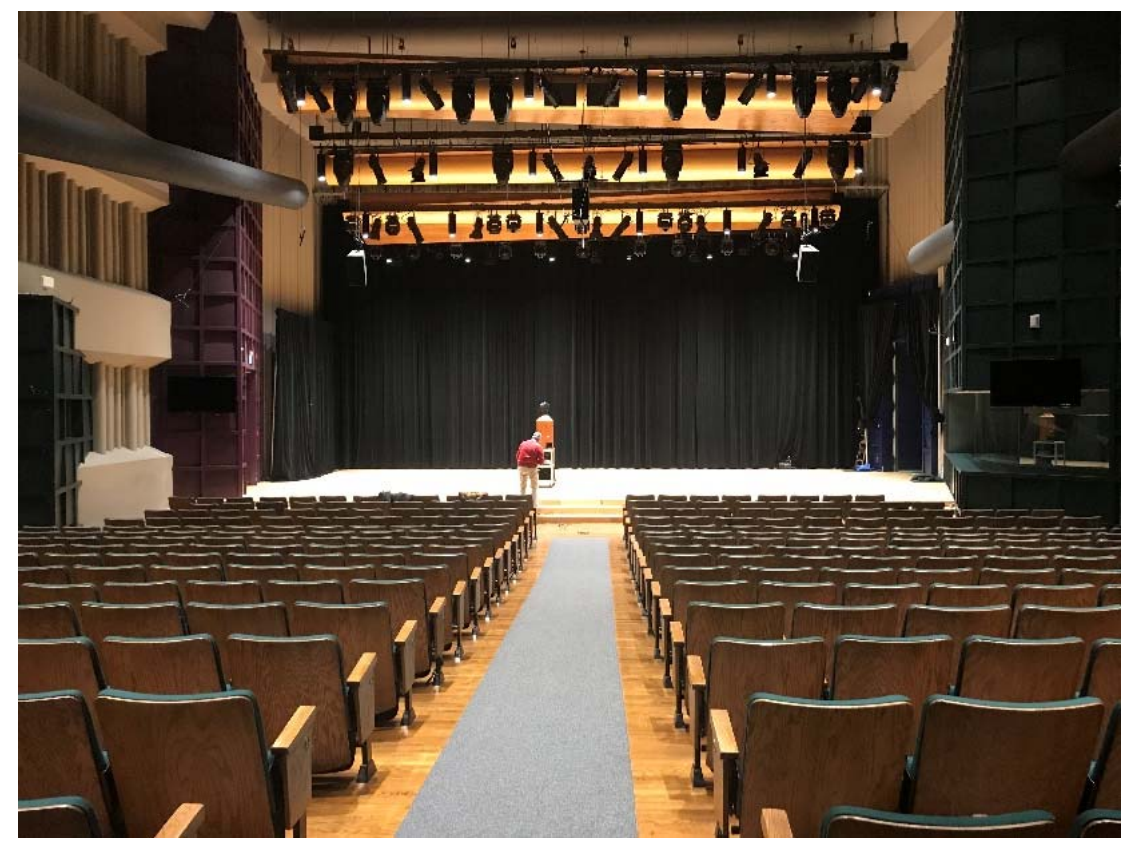

Figure 21: Picture of Stage Curtains Closed at Glenn Gould Studio 


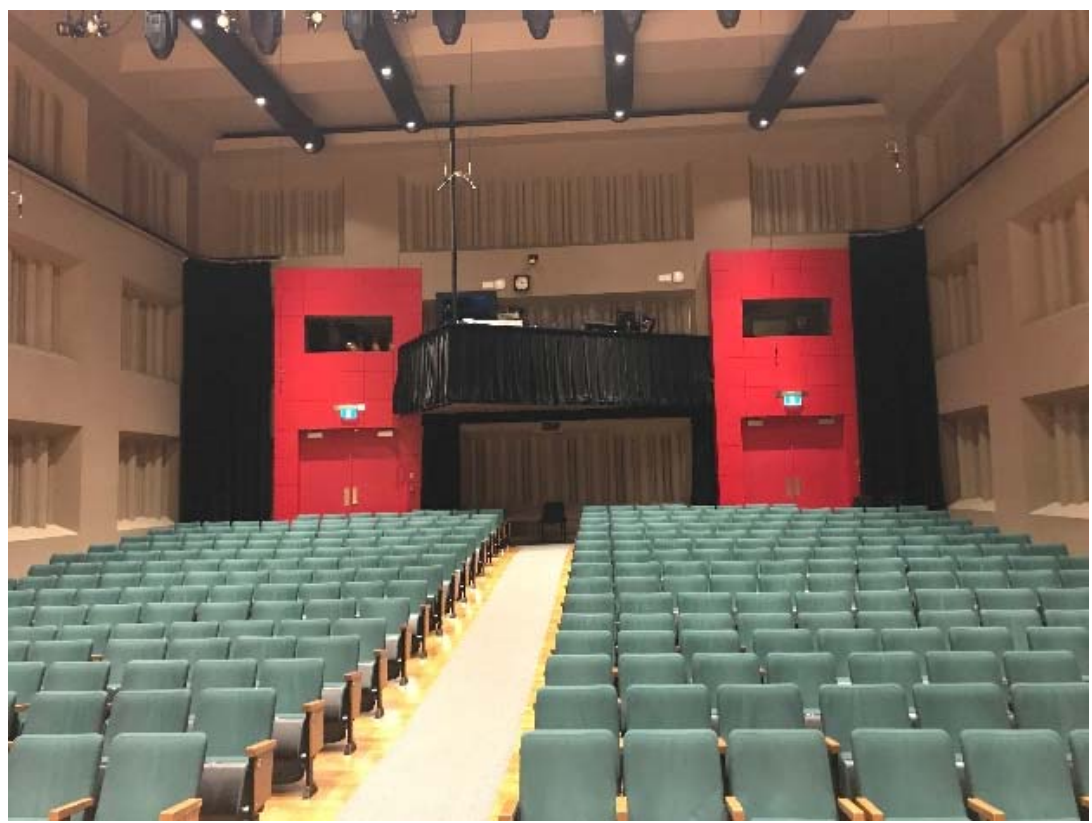

Figure 22: Picture of Side and Back Curtains open at Glenn Gould Studio

The Conditions and locations of the measurement in Glenn Gould Studio are summarized in Table 6 and Table 7.

Table 6: Summary of Measurement Conditions at Glenn Gould Studio

\begin{tabular}{|l|l|l|}
\hline & $\begin{array}{l}\text { Side \& Back } \\
\text { Curtains }\end{array}$ & $\begin{array}{l}\text { Stage } \\
\text { Curtains }\end{array}$ \\
\hline Condition 1 & Down & Down \\
\hline Condition 2 & Down & Up \\
\hline Condition 3 & Up & Up \\
\hline
\end{tabular}

Table 7: Measurement Locations at Glenn Gould Studio

\begin{tabular}{|l|l|}
\hline Location $\mathbf{1}$ \& $\mathbf{2}$ & Stage \\
\hline Location 3 & A8 \\
\hline Location 4 & D7 \\
\hline Location 5 & N8 \\
\hline
\end{tabular}


After the measurements were done for five different locations in the studio, the results for reverberation time for different locations and conditions are plotted. Figure 23 shows the results for location 3 which is a seating in front of the hall and Figure 24 shows the results for location 5 which is the seating in the back. The rest of the results for other locations including the stage locations can be found in Appendix $\mathrm{C}$ which shows the impact of stage curtains on the reverberation times.

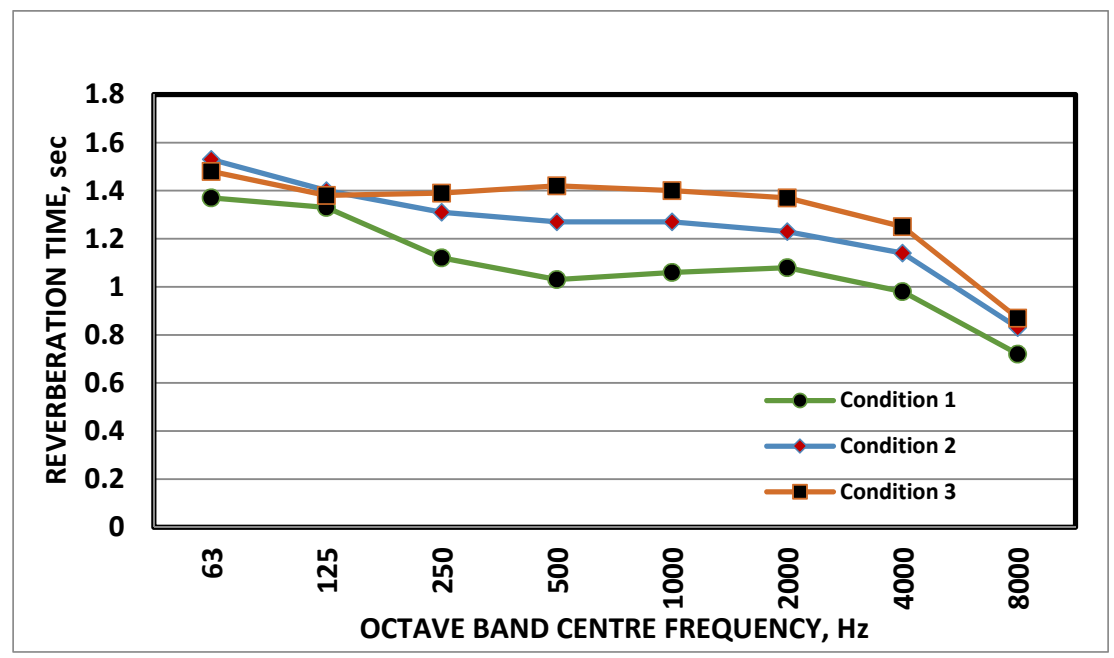

Figure 23: Reverberation Time Results for Location 3 at Glenn Gould Studio

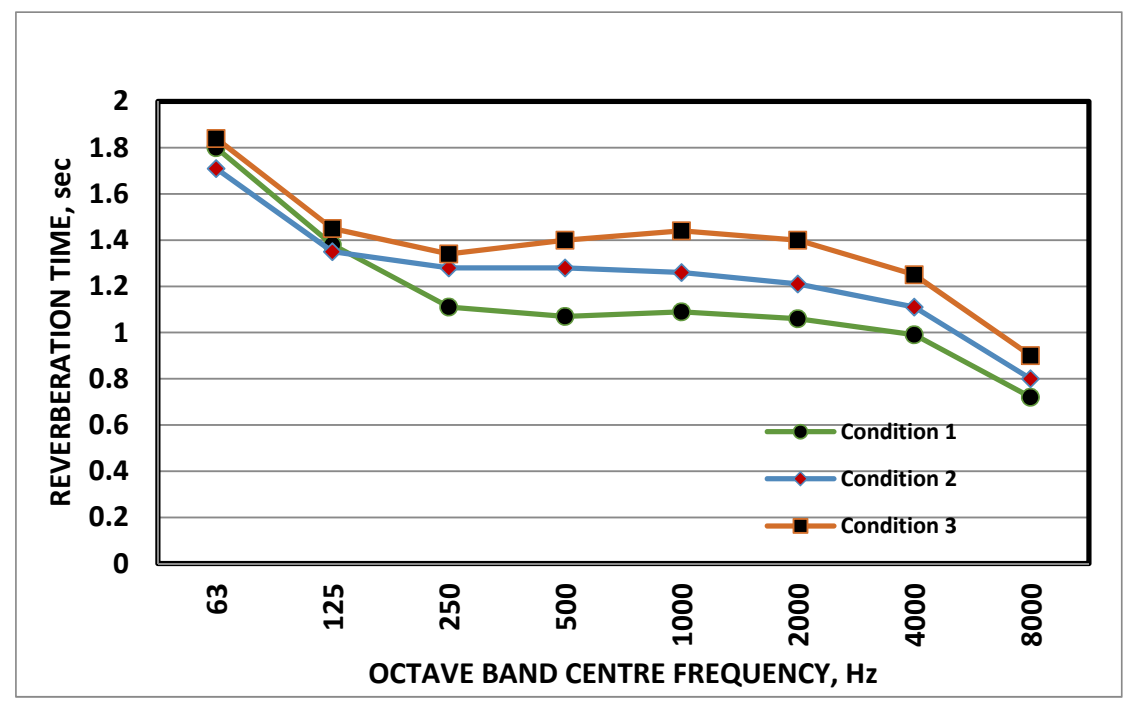

Figure 24: Reverberation Time Results for Location 5 at Glenn Gould Studio 
The measurement results show that the more curtain are in the less reverberation time. The curtains on the stage showed good impact even when the receiver location was at the back of the room. However, the change of reverberation time was only 0.35 seconds compared to other halls which had more significant change in reverberation time when the conditions are changed. Glenn Gould Studio has the capacity to be used for opera, ballet and chamber music.

\subsubsection{Summary of Passive Acoustics Results}

In summary using curtains on the side or back of the room changes the reverberation time. Adding absorptive material to the room decreases the reverberation time. The canopy above the stage and curtains behind the stage can have an impact on the reverberation time of the stage. By

changing the configuration of the curtains and the canopy, the auditoria can have the capacity to be used for variety of performances.

\subsection{Active Acoustics Results}

Among all the case studies that the measurements were done, one of them used active variable acoustics to control the acoustics of the room. Those measurements and results are discussed bellow.

\subsubsection{LIVELab}

Measurements were done in three different locations in the room, one being on the stage. The speaker was placed in the middle of the stage. The measurements were done in four different conditions. These conditions were when active control is off, classroom settings, Short Chamber (Small Ensemble), and concert hall. Figure 25 and Figure 26 show the interior of LIVElab from the stage and audience area. 


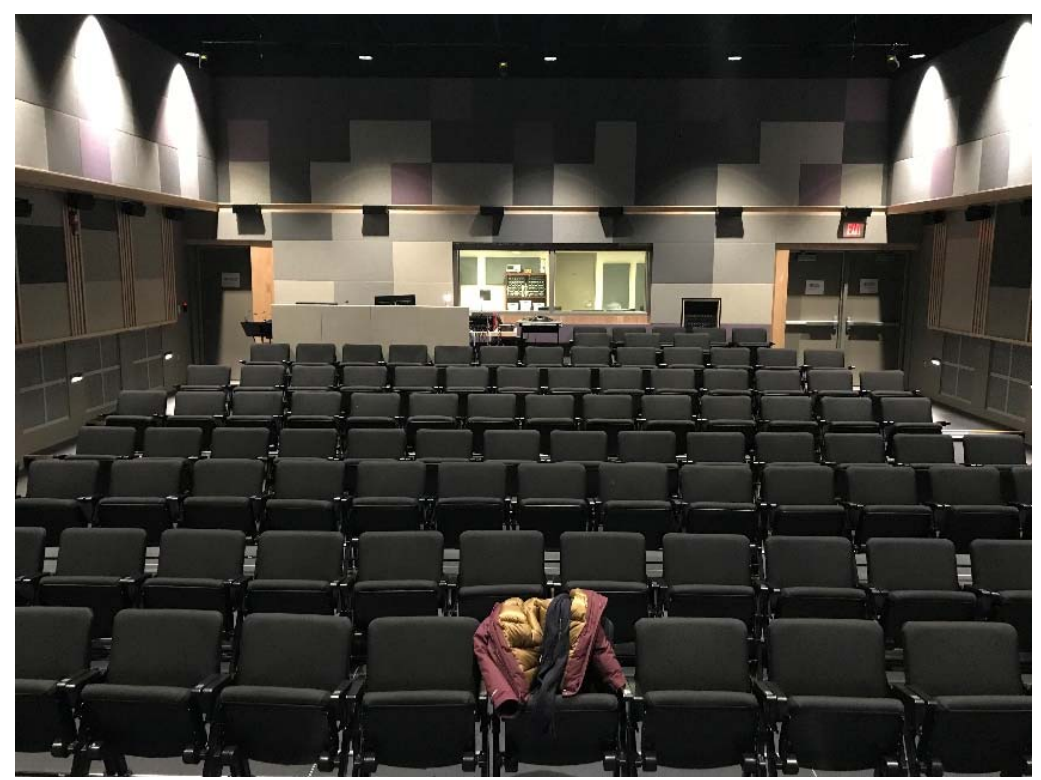

Figure 25: View of LIVELab from the Stage

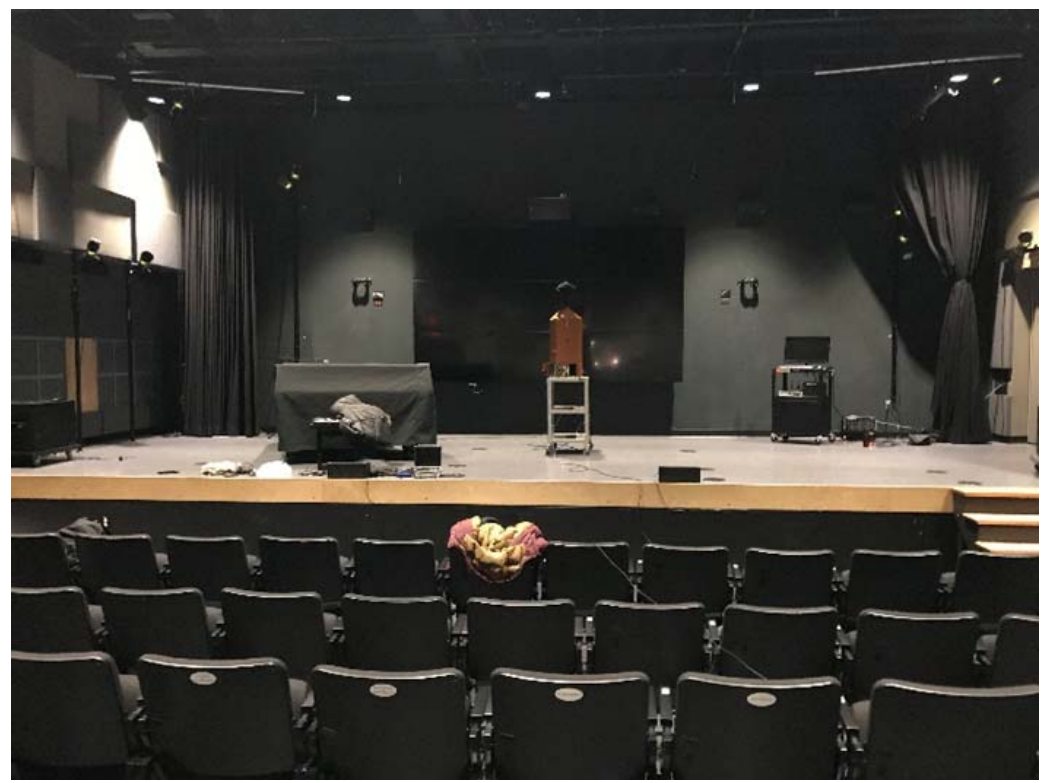

Figure 26: View of LIVELab Stage

The Conditions and locations of the measurement in LIVELab are summarized in Table 8 and Table 9. 


\section{Table 8: Summary of Measurement Conditions at LIVELab}

\begin{tabular}{|c|c|}
\hline Condition 1 & Active Control Off \\
\hline Condition 2 & Classroom \\
\hline Condition 3 & $\begin{array}{c}\text { Short Chamber (Small } \\
\text { Ensemble) }\end{array}$ \\
\hline Condition 4 & Concert Hall \\
\hline
\end{tabular}

Table 9: Measurement Locations at LIVELab

\begin{tabular}{|c|c|}
\hline Location 1 & Stage \\
\hline Location 2 & B9 \\
\hline Location 3 & F9 \\
\hline
\end{tabular}

After the measurements were done for four different locations in the studio, the results for reverberation time for different locations and conditions are plotted.

Figure 27 shows the results for location 2 which is a seating in front of the hall and Figure 28 shows the results for location 3 which is the seating in the back. Location 1 results can be found in Appendix D.

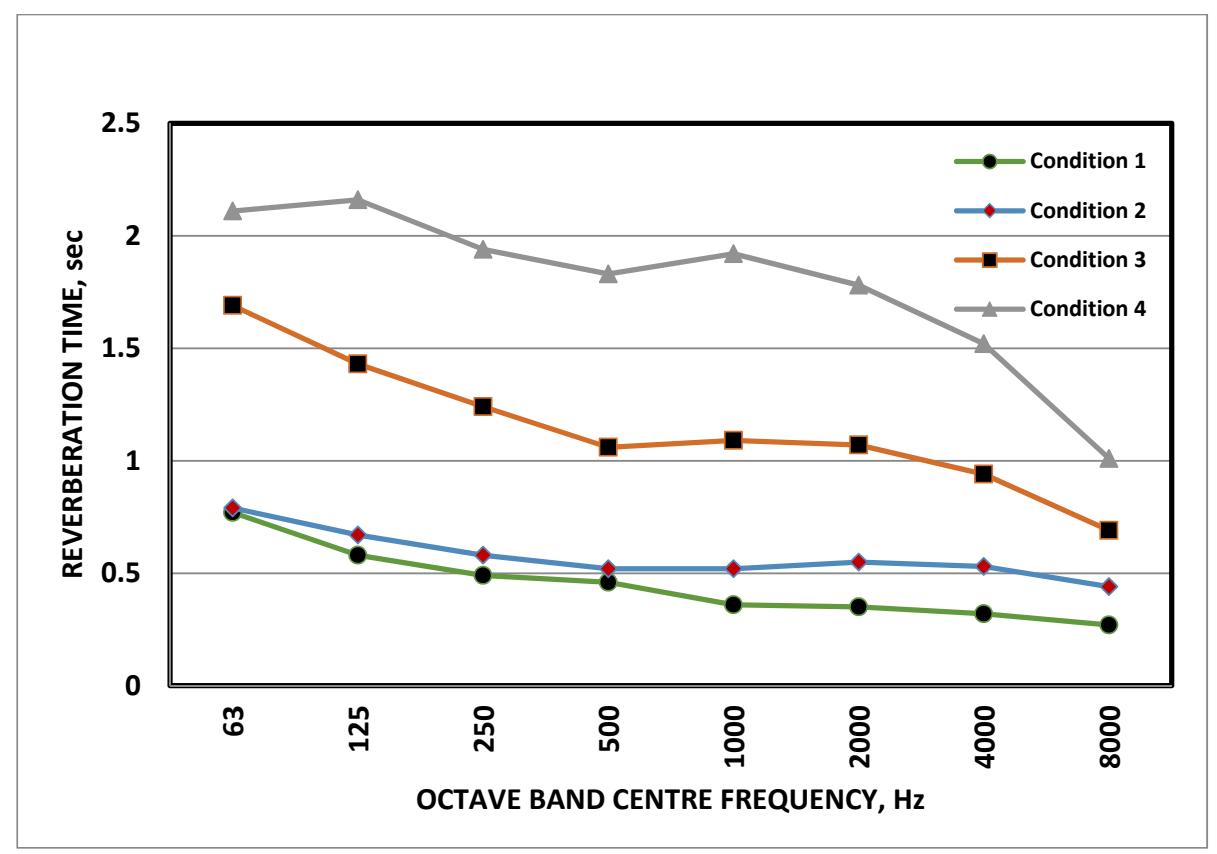

Figure 27: Reverberation Time Results for Location 2 at LIVELab 


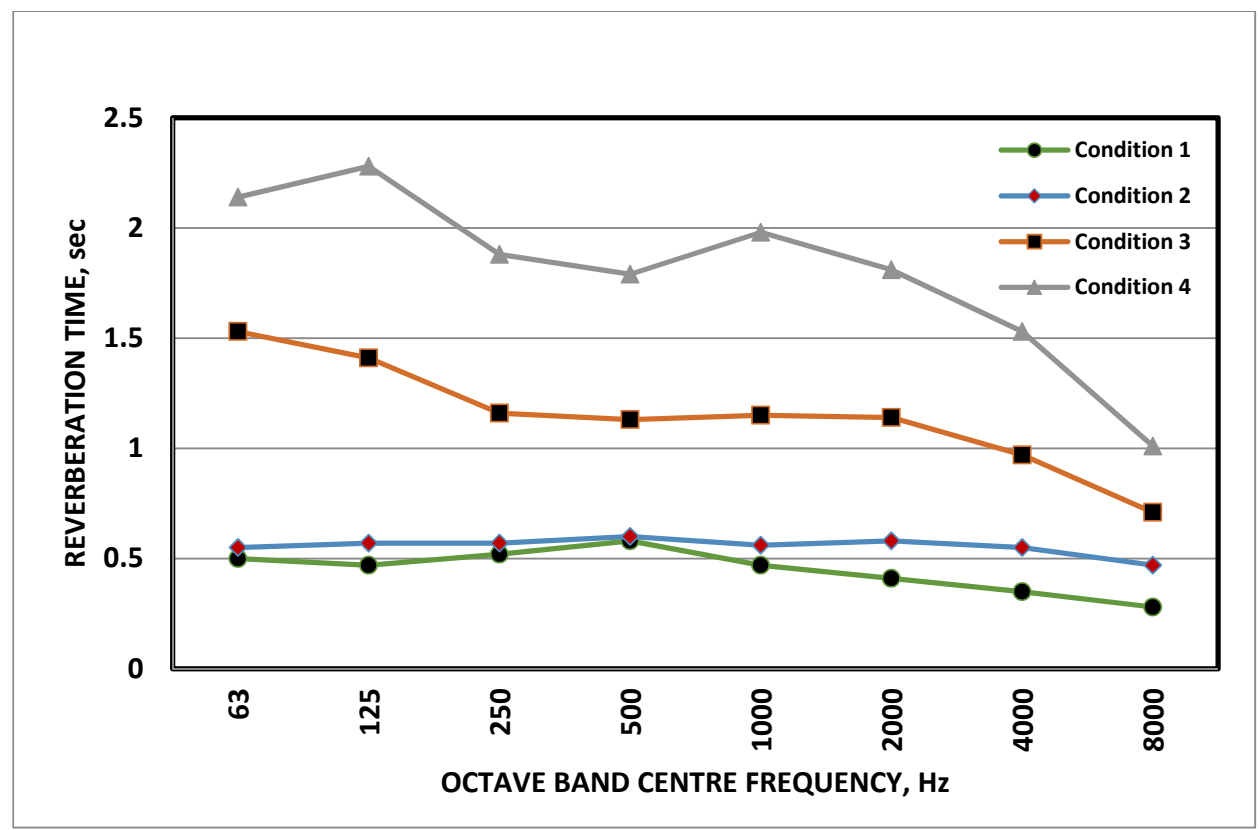

Figure 28: Reverberation Time Results for Location 3 at LIVELab

The measurement results show that when the active control in the room is off, the reverberation time is at its lowest and other conditions added reverberation time to the room. The results show that active acoustics system can only increase reverberation time in the room and it can not reduce it. Therefore, the bare room should be designed to be highly absorptive. Condition 2 which is a classroom setting shows reverberation time lower than 0.8 seconds which is ideal for a classroom setting. Condition 4 shows high reverberation time and can be used for concert hall as the settings suggested that as well. The reverberation time could be changed from 0.56 to 1.98 at $1000 \mathrm{~Hz}$ using active acoustics control. 


\subsection{Paul Cocker Gallery Application}

\subsection{Experimental Results}

The Gallery is constructed with framing and drywalls and one wall is mainly constructed of glazing. Therefore, the bare room would be highly reverberant. The four major uses that Gallery space can be used for are Exhibitions, crit space, presentation with the use of speakers and LCD, and a small chamber music with 30 seats and 4 musicians. Experiments were done using two, four, and six poster board panels. The poster board panels are highly absorptive structures that are filled with Rockwool insulation. The poster board panels are shown in Figure 29 along the glazing doors.

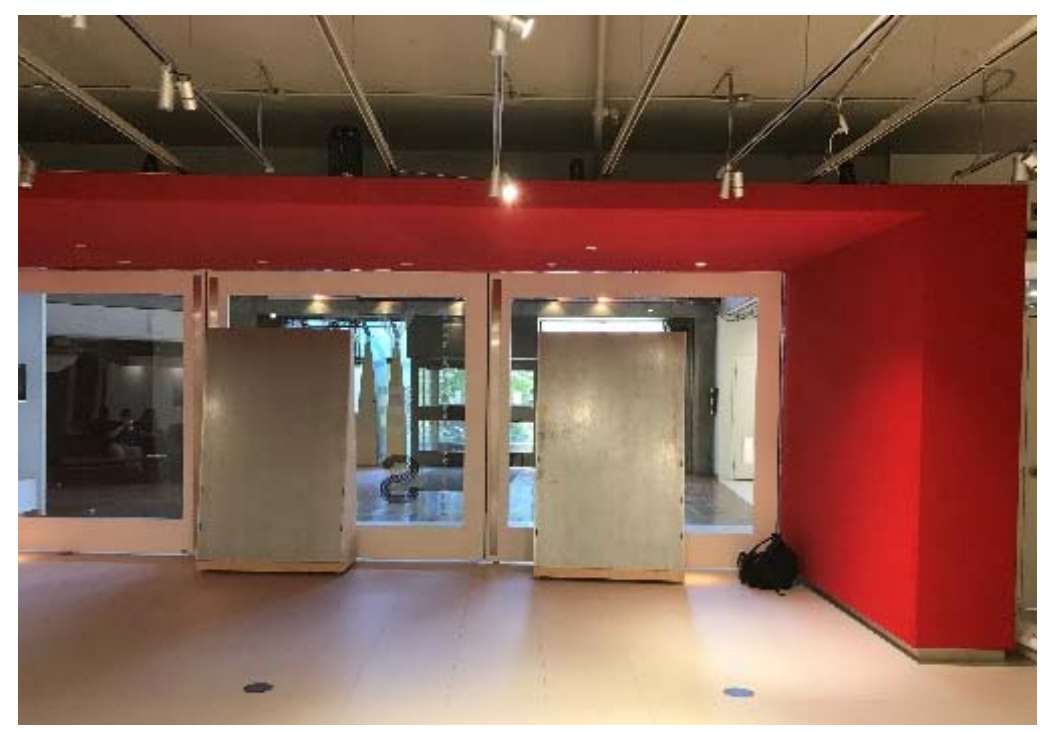

Figure 29: View of Poster Board Panels Used in Gallery

These boards are made of perforated sheet, Rockwool, and wood backing. The acoustic absorption of the poster board panels were measured using impedance poster tube. The boards are highly adsorptive and the absorption coefficient of them are shown in Table 10.

Table 10: Absorption Coefficient of the Poster Board Panels

\begin{tabular}{|c|c|c|c|c|c|c|c|c|}
\hline & $63 \mathrm{~Hz}$ & $125 \mathrm{~Hz}$ & $250 \mathrm{~Hz}$ & $500 \mathrm{~Hz}$ & $1000 \mathrm{~Hz}$ & $2000 \mathrm{~Hz}$ & $4000 \mathrm{~Hz}$ & $8000 \mathrm{~Hz}$ \\
\hline $\begin{array}{c}\text { Poster Board } \\
\text { Panels }\end{array}$ & 0.51 & 0.71 & 0.84 & 0.84 & 0.85 & 0.96 & 0.96 & 0.96 \\
\hline
\end{tabular}


The first experiment using sine-sweep signal was done in the bare gallery without any poster board panels. Figure 30 shows the source and receiver locations in the gallery.

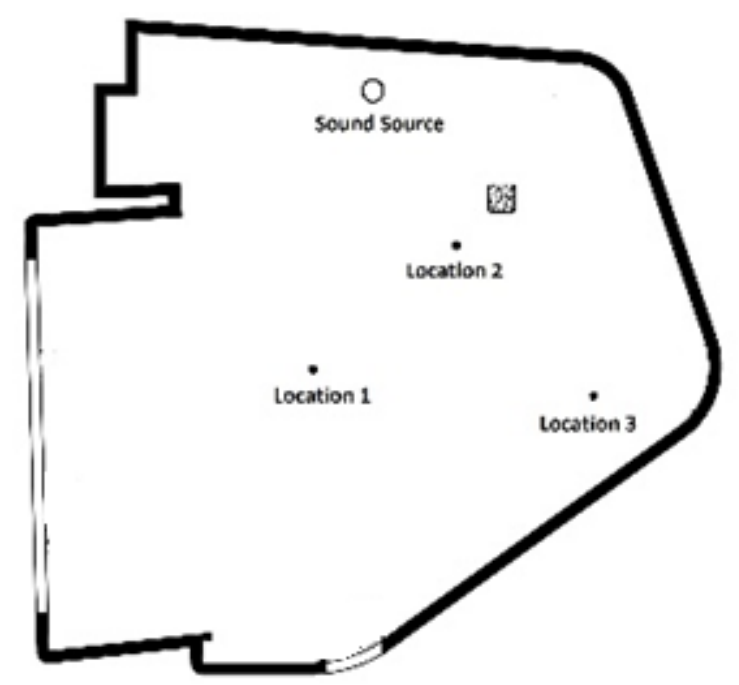

Figure 30: Paul Cocker Gallery Bare room Source and Receiver Locations

In addition, a picture of source location is shown in Figure 31.

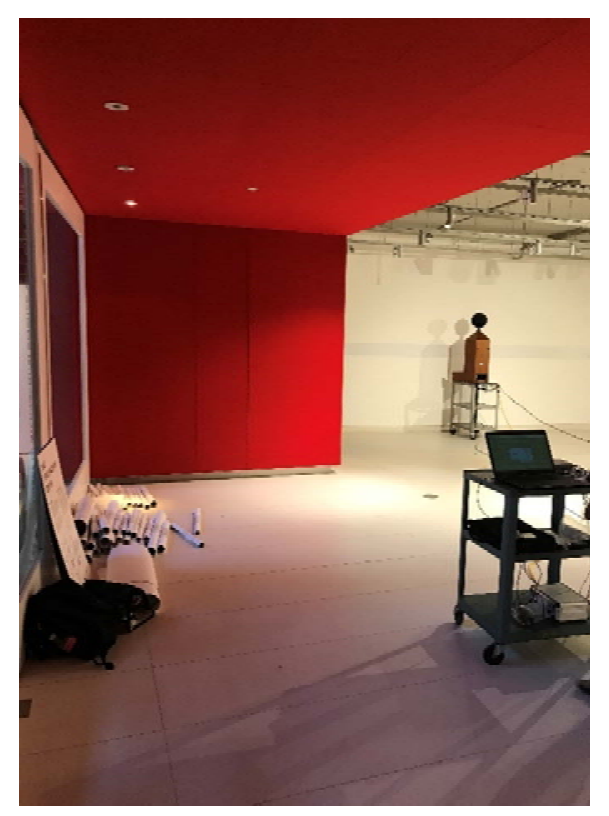

Figure 31: Picture of Gallery Source Location 
After the measurements of the bare room, measurements were done at the same location using two, four, and six poster board panels. Figure 32 through Figure 34 show these different conditions with the location of the poster board panels, sound source, and receiver.

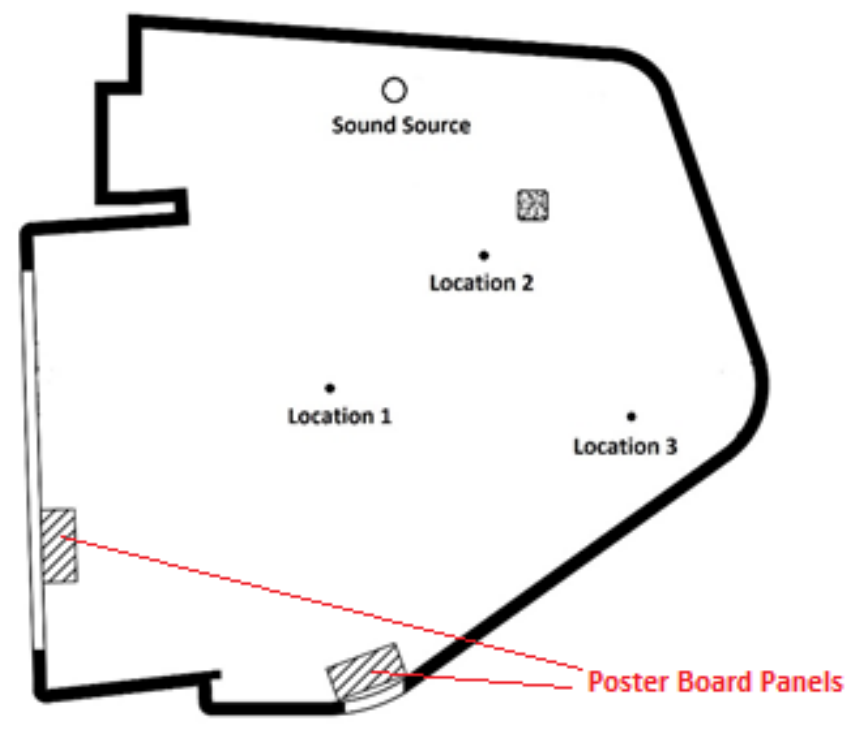

Figure 32: Paul H Cocker Gallery Two Poster Board Locations

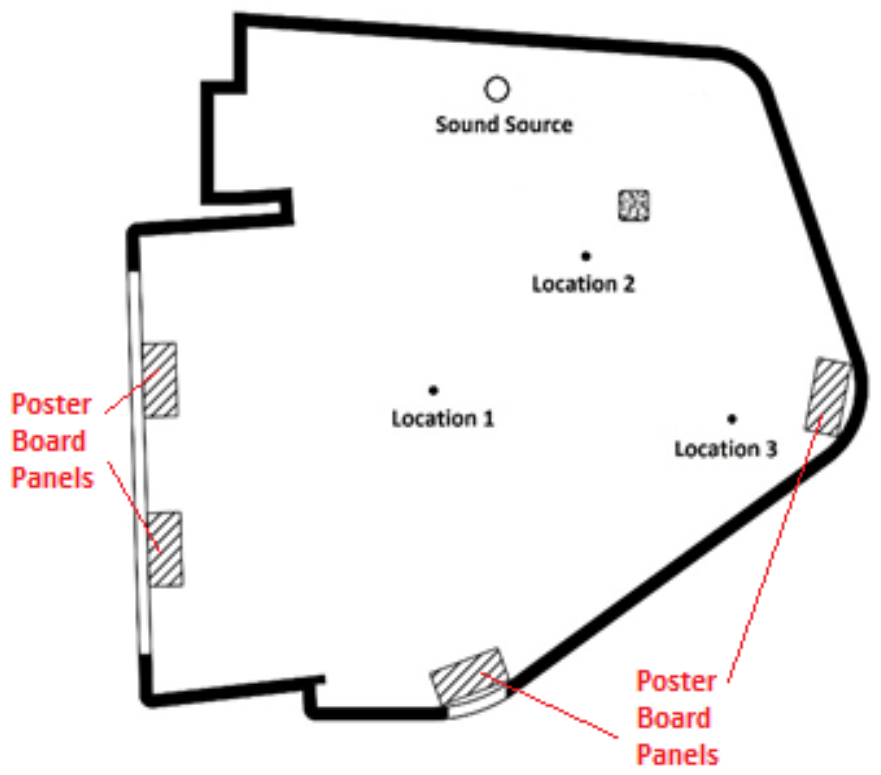

Figure 33: Paul H Cocker Gallery Four Poster Board Locations 


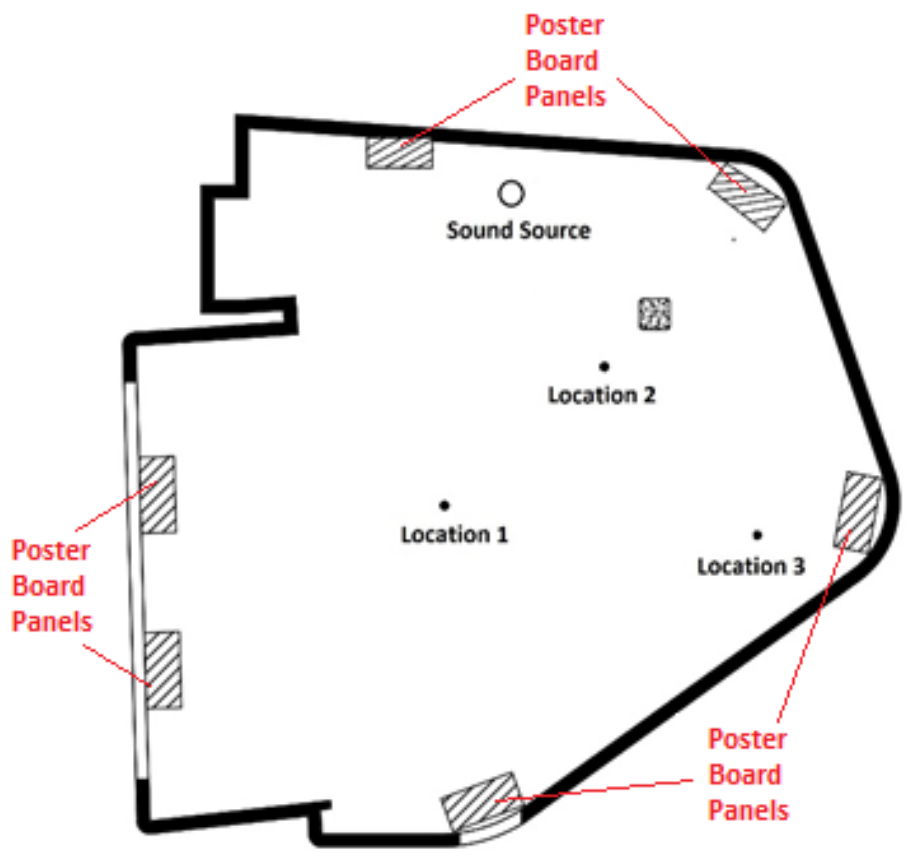

Figure 34: Paul H Cocker Gallery Six Poster Board Location

The results of the reverberation time measurements for location 1,2 and 3 are summarized in the graphs of Figure 35 through Figure 37. Each graph shows the reverberation time for the each location with different number of poster board panels moved into the Gallery.

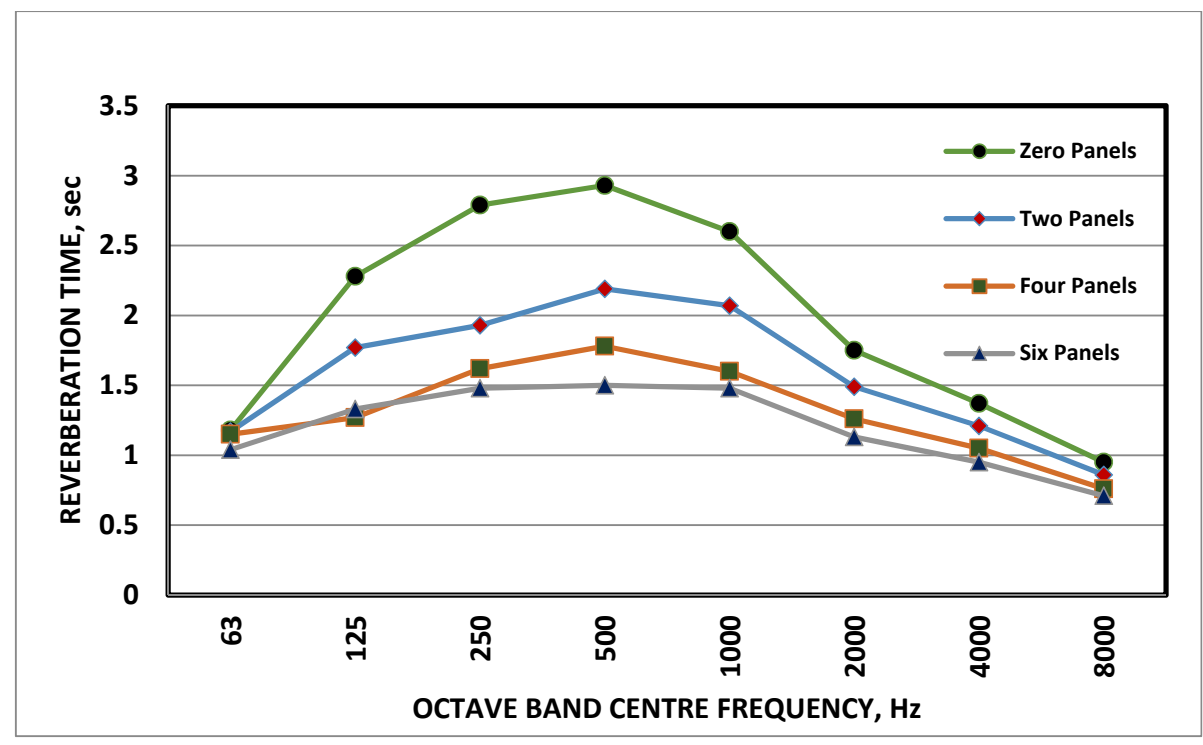

Figure 35: Reverberation Time Results for Location 1 


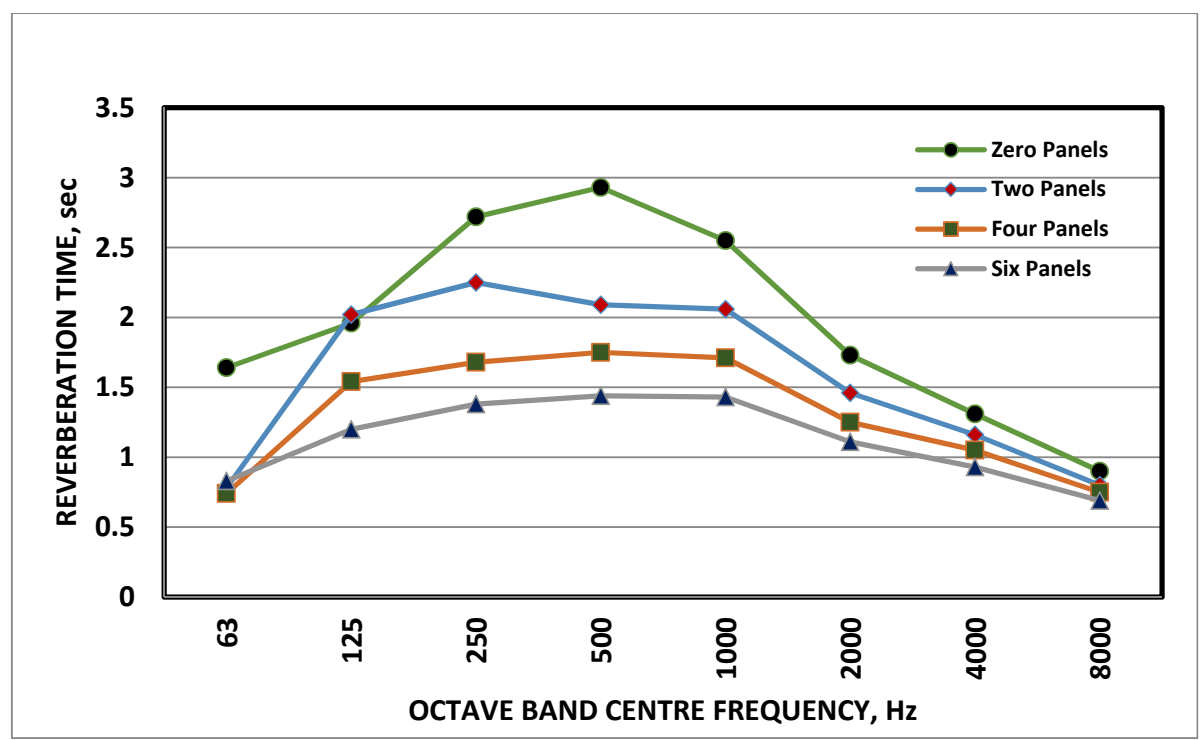

Figure 36: Reverberation Time Results for Location 2

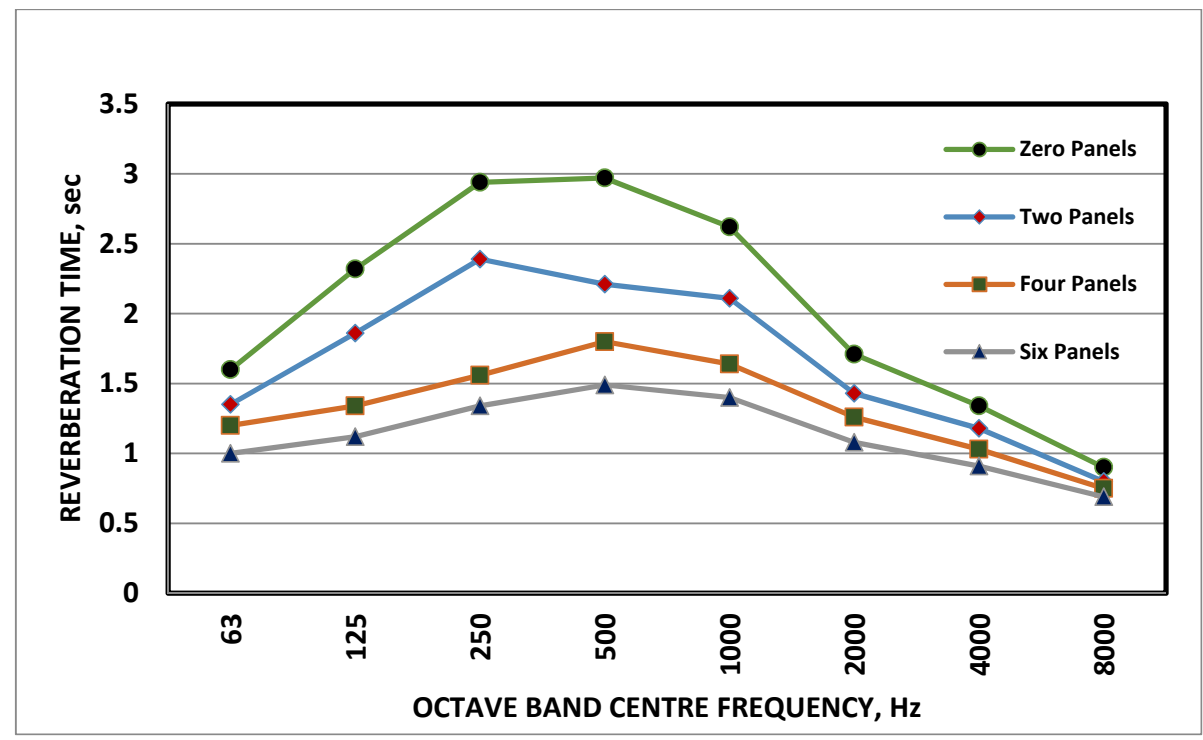

Figure 37: Reverberation Time Results for Location 3

The results show that the reverberation time is approximately similar in the three locations that measurements were done. Zero panels or bare room condition will be used to validate the ODEON simulation results. Bare room has the most reverberation time compared to the other conditions with approximately 2.6 seconds at $1000 \mathrm{~Hz}$. When two panels are added, the 
reverberation time is decreased and became in average 2.07 seconds at $1000 \mathrm{~Hz}$. When four poster board panels are present in the room, the reverberation time for $1000 \mathrm{~Hz}$ becomes 1.64 seconds. This set up can used for small chamber music with 30 seats and 4 musicians. Finally, when six poster boards are added to the room, it can be suitable for lecture hall and presentations with sound systems and LCD. Since the reverberation time in most of the frequencies are higher than the required RT for the lecture hall, it is suggested to add two more panels to the room to make it better suitable for lecture halls. Using eight poster board panels is also suitable for a crit space.

Speech transmission index is an important factor in a classroom type room. The STI between 0.75 and 1.0 indicates an excellent intelligibility rating. Table 11 shows the STI for the different conditions and receivers. The maximum STI rating measured was 0.62 . This shows that the STI in the Gallery is poor but adding more panels made the STI to increase slightly.

Table 11 : Gallery STI Measurements Results

\begin{tabular}{|l|l|l|l|l|}
\hline & $\begin{array}{l}\text { Bare } \\
\text { Room }\end{array}$ & 2 Panels & 4 Panels & 6 Panels \\
\hline Location 1 & 0.47 & 0.5 & 0.53 & 0.59 \\
\hline Location 2 & 0.5 & 0.53 & 0.58 & 0.62 \\
\hline Location 3 & 0.5 & 0.53 & 0.57 & 0.58 \\
\hline
\end{tabular}

\subsection{Simulation Results}

ODEON software was used to evaluate the sound distribution in the Gallery. The Gallery's bare room was validated first in order to get acceptable results for the additional simulations. 


\subsubsection{Bare Room Validation}

The reverberation time measured using the sine-sweep signal, were used to validate the computer simulation. The measured reverberation time from the on-site measurements were matched for the simulation. The chosen material of the room surfaces were from the ODEON software database. Table 12 shows the absorption coefficient for the material used in the Gallery. The reverberation times were validated by modifying the surface coefficients in order to get the results to be as close as possible to the measured numbers.

Table 12: Gallery Material Absorption Coefficients

\begin{tabular}{|c|c|c|c|c|c|c|c|c|}
\hline Materials & $63 \mathrm{~Hz}$ & $125 \mathrm{~Hz}$ & $250 \mathrm{~Hz}$ & $500 \mathrm{~Hz}$ & $1000 \mathrm{~Hz}$ & $2000 \mathrm{~Hz}$ & $4000 \mathrm{~Hz}$ & $8000 \mathrm{~Hz}$ \\
\hline Wall & 0.28 & 0.28 & 0.12 & 0.10 & 0.17 & 0.13 & 0.09 & 0.09 \\
\hline Floor & 0.02 & 0.02 & 0.02 & 0.03 & 0.04 & 0.04 & 0.05 & 0.05 \\
\hline Ceiling & 0.01 & 0.01 & 0.01 & 0.02 & 0.02 & 0.05 & 0.05 & 0.05 \\
\hline Felt & 0.03 & 0.03 & 0.09 & 0.25 & 0.31 & 0.33 & 0.44 & 0.44 \\
\hline Glass & 0.08 & 0.08 & 0.04 & 0.03 & 0.03 & 0.02 & 0.02 & 0.05 \\
\hline Concrete & 0.01 & 0.01 & 0.01 & 0.02 & 0.02 & 0.02 & 0.05 & 0.05 \\
\hline
\end{tabular}

Figure 38 shows the ODEON set up for the Gallery. The sound source location is indicated using P1. 


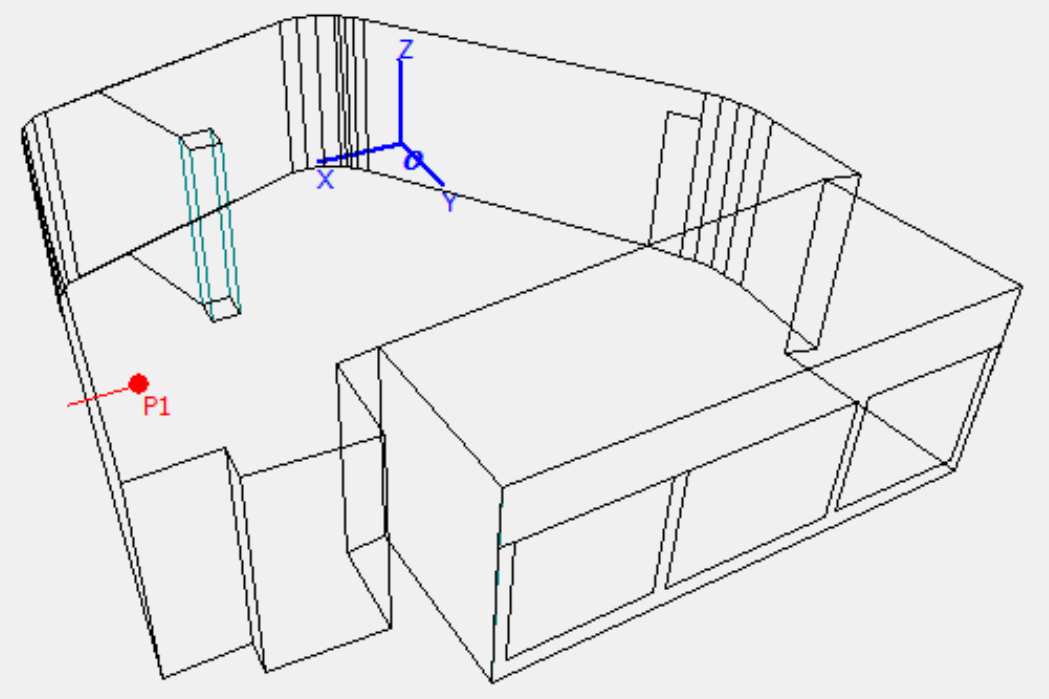

Figure 38: ODEON Set-up of Bare Gallery

After doing the adjustments for the materials and simulating the bare room, the RT results were validated. Table 13 shows the average measured reverberation time vs the average simulated reverberation time.

Table 13: Measured and Validated RT for Bare Gallery

\begin{tabular}{|c|c|c|c|c|c|c|c|c|}
\hline Reverberation Time (s) & $63 \mathrm{~Hz}$ & $125 \mathrm{~Hz}$ & $250 \mathrm{~Hz}$ & $500 \mathrm{~Hz}$ & $1000 \mathrm{~Hz}$ & $2000 \mathrm{~Hz}$ & $4000 \mathrm{~Hz}$ & $8000 \mathrm{~Hz}$ \\
\hline Bare Room Measured & 1.64 & 1.96 & 2.72 & 2.93 & 2.55 & 1.73 & 1.37 & 0.90 \\
\hline Bare Room Simulated & 1.84 & 1.88 & 2.74 & 2.31 & 2.25 & 1.70 & 1.39 & 0.87 \\
\hline
\end{tabular}

The results show that the simulation gives a data that is within the acceptable range as the majority are within the 10 to $15 \%$ of the engineering precision.

\subsubsection{Room with Poster Board Panels}

After the Validation is done, Gallery is modeled using two, four, six and ten panels. Figure 39 shows the modeled room with two poster board panels. P1 is the speaker and points 1,2 and 3 
are the locations that measurements were done in gallery. Other configurations follow the same locations that were measured and shown in section 5.1.

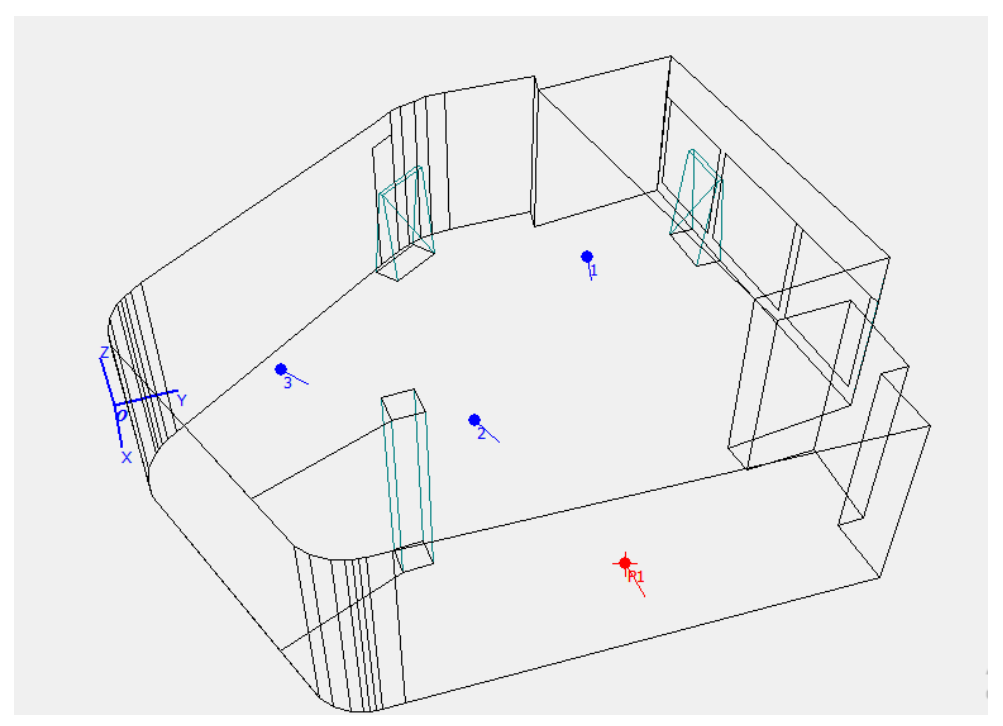

Figure 39: Gallery Modeled with Two Poster Board Panels

Absorption coefficient for the poster boards were imputed into ODEON software as a new material. The absorption coefficient for the poster boards are used based on the measurements that were done in a research by Eva Johnston-Iafelice [17]. These absorption coefficients were measured using impedance tube. The impedance tube measures sound absorption coefficient and sound transmission loss, in addition to other acoustic properties of porous materials. Table 14 shows the absorption coefficient of the poster board panels.

Table 14: Absorption Coefficient of the Poster Board Panels

\begin{tabular}{|c|c|c|c|c|c|c|c|c|}
\hline & $63 \mathrm{~Hz}$ & $125 \mathrm{~Hz}$ & $250 \mathrm{~Hz}$ & $500 \mathrm{~Hz}$ & $1000 \mathrm{~Hz}$ & $2000 \mathrm{~Hz}$ & $4000 \mathrm{~Hz}$ & $8000 \mathrm{~Hz}$ \\
\hline $\begin{array}{c}\text { Poster Board } \\
\text { Panels }\end{array}$ & 0.51 & 0.71 & 0.84 & 0.84 & 0.85 & 0.96 & 0.96 & 0.96 \\
\hline
\end{tabular}

After doing the simulations for two, four and six panels in the gallery, the simulated results for reverberation time can be seen in Figure 40 for location 1. 


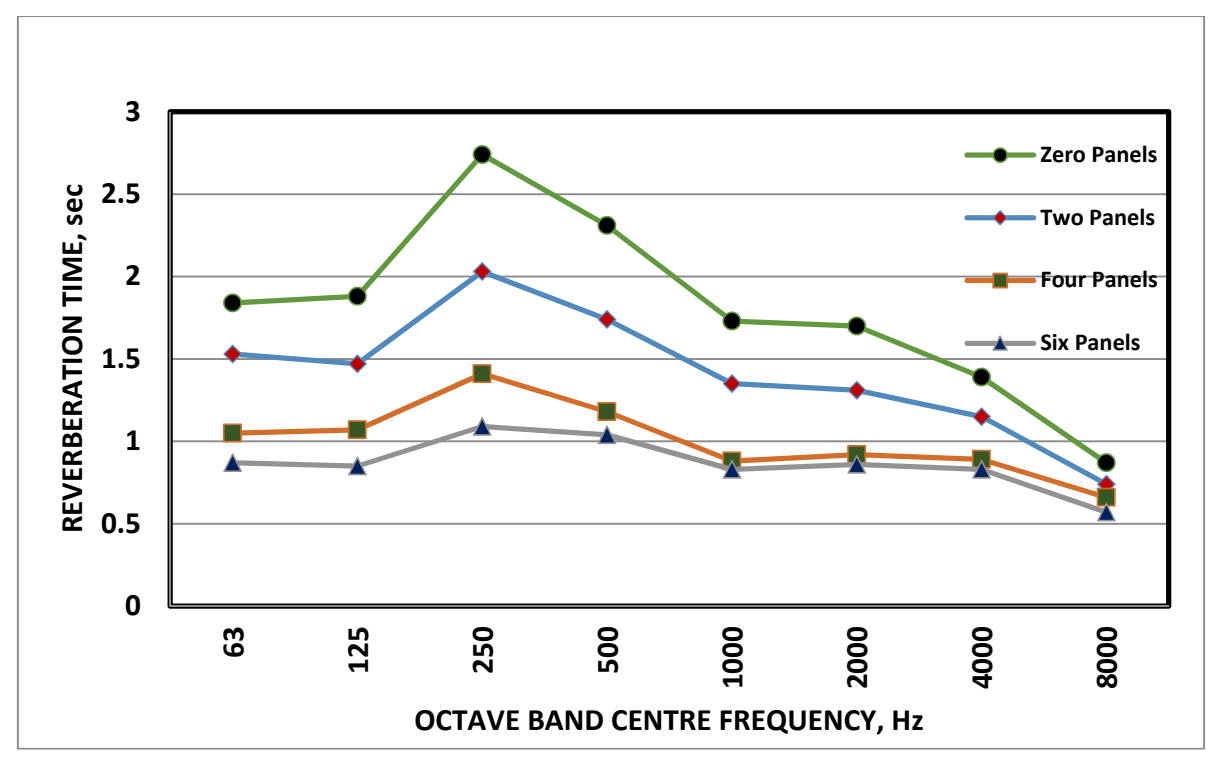

Figure 40: Reverberation Time Simulation Results

The results shows that as more panels are added to the room, the reverberation time decreases and this was proven by doing both on-site measurements and simulations.

As it was learned from measurements done in the LIVElab, in order to apply the active acoustics method, the reverberation time can only be added and can not be reduced. Thus, if this method is used in the Gallery, first the reverberation time in that space should be refined to become as short as possible. This means we have to add a lot of poster boards in the room. Therefore, the simulation was done using twelve poster board panels in order to make the reverberation time as close to zero as possible. The results of the simulation is shown in Table 15 .

Table 15: Reverberation Time of Gallery Using 12 Panels

\begin{tabular}{|c|c|c|c|c|c|c|c|c|}
\hline Reverberation Time (s) & $63 \mathrm{~Hz}$ & $125 \mathrm{~Hz}$ & $250 \mathrm{~Hz}$ & $500 \mathrm{~Hz}$ & $1000 \mathrm{~Hz}$ & $2000 \mathrm{~Hz}$ & $4000 \mathrm{~Hz}$ & $8000 \mathrm{~Hz}$ \\
\hline $\begin{array}{c}\text { Gallery with 12 panels } \\
\text { Simulated }\end{array}$ & 0.68 & 0.53 & 0.65 & 0.63 & 0.55 & 0.57 & 0.56 & 0.44 \\
\hline
\end{tabular}




\section{Table 16: STI of Gallery Using 12 Panels}

\begin{tabular}{|c|c|}
\hline & 12 Panels \\
\hline Location 1 & 0.72 \\
\hline Location 2 & 0.76 \\
\hline Location 3 & 0.72 \\
\hline
\end{tabular}

The simulation results show that the room reverberation time can be decreased to be used for active acoustics system. However, the room would be crammed with the poster board panels since in minimum twelve panels are needed. The STI of the room with the addition of 12 panels is in average 0.73 which is still less than 0.75 and shows that STI of the room is not in the excellent range.

\subsubsection{Room with Acoustic Panels}

In order to see if adding acoustical panels to the wall can have an effect on the reverberation time of the room, simulations were done using 2 inch AlphaSorb acoustic panels that can be attached to the walls. Table 17 sows the absorption coefficient of the acoustic panels used.

Table 17: Absorption Coefficient of the Acoustic Panels

\begin{tabular}{|c|c|c|c|c|c|c|c|c|}
\hline & $63 \mathrm{~Hz}$ & $125 \mathrm{~Hz}$ & $250 \mathrm{~Hz}$ & $500 \mathrm{~Hz}$ & $1000 \mathrm{~Hz}$ & $2000 \mathrm{~Hz}$ & $4000 \mathrm{~Hz}$ & $8000 \mathrm{~Hz}$ \\
\hline $\begin{array}{c}2 \text { inch Acoustic } \\
\text { Panels }\end{array}$ & 0.1 & 0.22 & 0.81 & 1.0 & 1.0 & 1.0 & 1.0 & 1.0 \\
\hline
\end{tabular}

First, the panels were added wherever the felt surfaces were in the room. Figure 41 shows the location of added acoustical panels in red and Table 18 shows the RT results for the three receiver locations in the Gallery. 


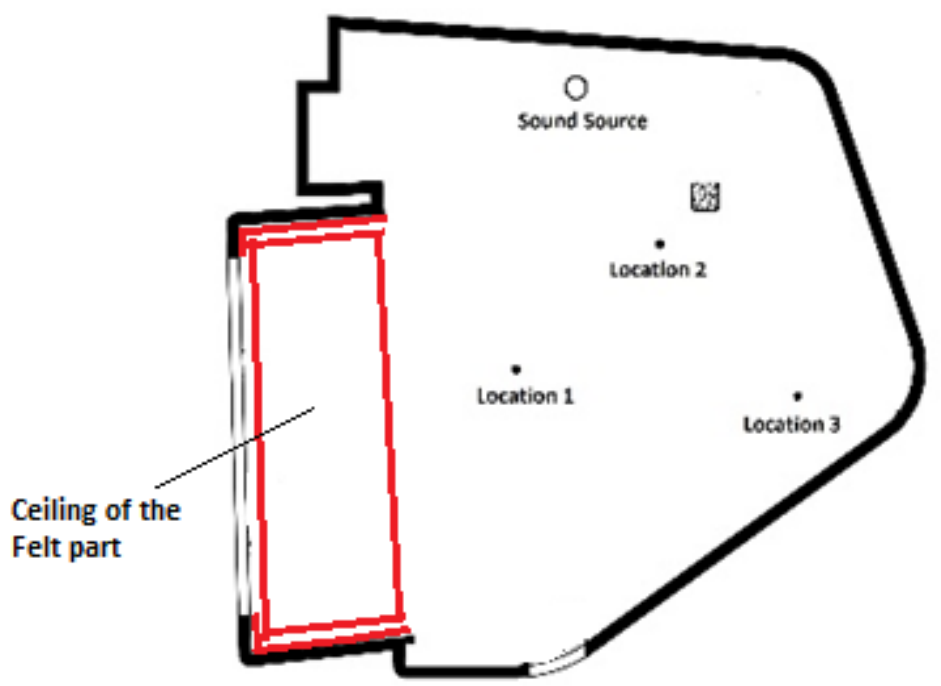

Figure 41: Location of Added Acoustic Panels on the Felt Part

Table 18: RT Results of Adding Acoustical Panels on Felt Part

\begin{tabular}{|c|c|c|c|c|c|c|c|c|}
\hline $\begin{array}{c}\text { Reverberation } \\
\text { Time (s) }\end{array}$ & $63 \mathrm{~Hz}$ & $\mathbf{1 2 5 \mathrm { Hz }}$ & $\mathbf{2 5 0 \mathrm { Hz }}$ & $\mathbf{5 0 0 \mathrm { Hz }}$ & $\mathbf{1 0 0 0 \mathrm { Hz }}$ & $\mathbf{2 0 0 0 \mathrm { Hz }}$ & $\mathbf{4 0 0 0 \mathrm { Hz }}$ & $\mathbf{8 0 0 0} \mathrm{Hz}$ \\
\hline Location 1 & 1.69 & 1.53 & 1.48 & 1.44 & 1.07 & 1.16 & 1.08 & 0.71 \\
\hline Location 2 & 1.7 & 1.51 & 1.39 & 1.29 & 1.06 & 1.11 & 1.05 & 0.73 \\
\hline Location 3 & 1.72 & 1.53 & 1.4 & 1.33 & 1.15 & 1.21 & 1.13 & 0.73 \\
\hline
\end{tabular}

The results show that adding acoustical panels instead of the felt part reduces the reverberation time but the value is still not good enough for a classroom and presentations setting since it s more than 0.8 seconds. However, this set up is sufficient to be use for a small chamber music room.

Second, more panels were added to the wall on the right side of the doors. Figure 42 shows the location of added acoustical panels and Table 19 shows the RT results for the three receiver locations in the Gallery. 


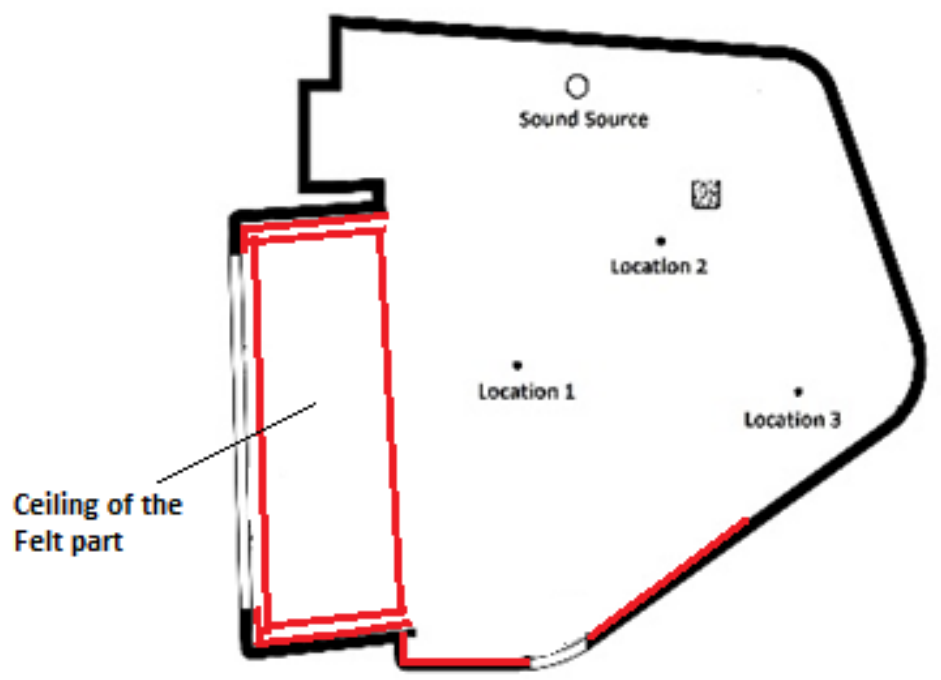

Figure 42: Location of Added Acoustic Panels on the Felt Part and Wall 1

Table 19: RT Results of Adding Acoustical Panels on Felt Part and Wall 1

\begin{tabular}{|c|c|c|c|c|c|c|c|c|}
\hline $\begin{array}{c}\text { Reverberation } \\
\text { Time (s) }\end{array}$ & $63 \mathrm{~Hz}$ & $\mathbf{1 2 5 \mathrm { Hz }}$ & $\mathbf{2 5 0 \mathrm { Hz }}$ & $\mathbf{5 0 0 \mathrm { Hz }}$ & $\mathbf{1 0 0 0 \mathrm { Hz }}$ & $\mathbf{2 0 0 0 \mathrm { Hz }}$ & $\mathbf{4 0 0 0 \mathrm { Hz }}$ & $\mathbf{8 0 0 0 \mathrm { Hz }}$ \\
\hline Location 1 & 1.58 & 1.26 & 0.76 & 0.6 & 0.52 & 0.55 & 0.56 & 0.46 \\
\hline Location 2 & 1.57 & 1.26 & 0.85 & 0.88 & 0.61 & 0.74 & 0.76 & 0.47 \\
\hline Location 3 & 1.6 & 1.27 & 0.79 & 0.61 & 0.55 & 0.58 & 0.58 & 0.44 \\
\hline
\end{tabular}

The results show that the reverberation time in this setting is decreased. Since the reverberation time now became less than 0.8 seconds, this set up can be used for classroom setting and crit.

Third, more panels were added to the wall behind the speaker location. Figure 43 shows the location of added acoustical panels and Table 20 shows the RT results for the three receiver locations in the Gallery. 


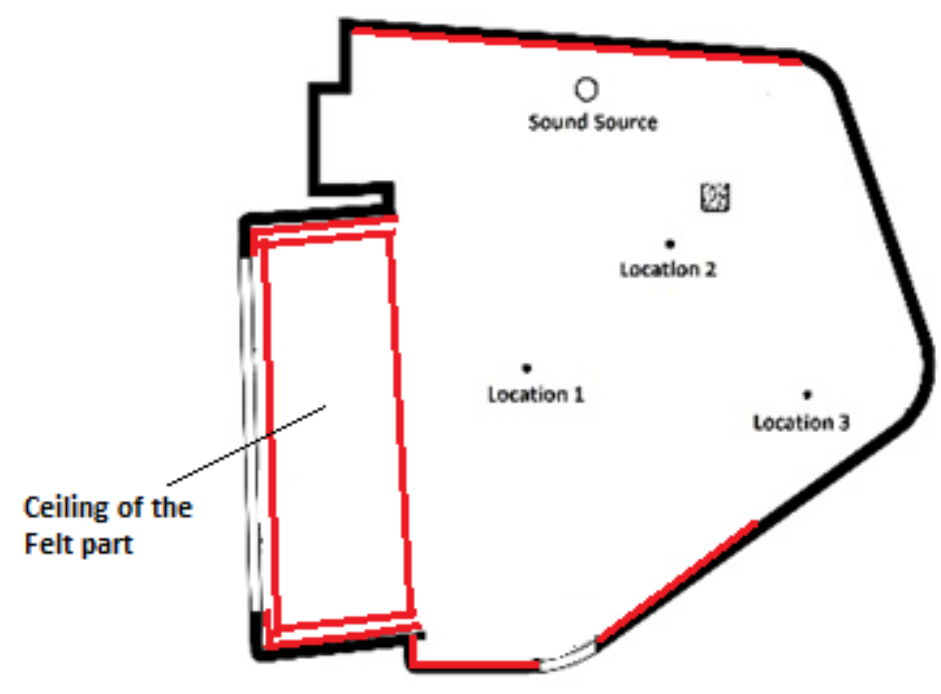

Figure 43: Location of Added Acoustic Panels on the Felt Part and Wall 1 and 2

Table 20: RT Results of Adding Acoustical Panels on Felt Part and Wall 1 and 2

\begin{tabular}{|c|c|c|c|c|c|c|c|c|}
\hline $\begin{array}{c}\text { Reverberation } \\
\text { Time (s) }\end{array}$ & $\mathbf{6 3} \mathrm{Hz}$ & $\mathbf{1 2 5} \mathrm{Hz}$ & $\mathbf{2 5 0 \mathrm { Hz }}$ & $\mathbf{5 0 0 \mathrm { Hz }}$ & $\mathbf{1 0 0 0 \mathrm { Hz }}$ & $\mathbf{2 0 0 0 \mathrm { Hz }}$ & $\mathbf{4 0 0 0 \mathrm { Hz }}$ & $\mathbf{8 0 0 0} \mathrm{Hz}$ \\
\hline Location 1 & 1.48 & 1.11 & 0.62 & 0.63 & 0.49 & 0.55 & 0.56 & 0.42 \\
\hline Location 2 & 1.48 & 1.12 & 0.96 & 1.12 & 0.76 & 0.91 & 0.92 & 0.42 \\
\hline Location 3 & 1.5 & 1.14 & 0.65 & 0.7 & 0.4 & 0.5 & 0.53 & 0.35 \\
\hline
\end{tabular}

The results show that adding acoustic panels to wall 2 did not have a lot of impact in decreasing the reverberation time comparing to the last setting of only having panels on wall 1 and felt part. However, this setting can be used for classroom, crit and exhibitions. It is recommended to use less of the acoustic panels on the walls since posters are attached to the walls of the Gallery and using the panels can limit the area where posters can be attached. Therefore, using acoustic panels on wall 1 and the felt part is the best solution for the use of the gallery for crit and exhibitions. 


\subsection{Conclusions}

The main focus of this research was to investigate the possibility of applying passive variable acoustics and active variable acoustics to control the performance of the Paul H. Cocker Gallery for the multipurpose functionality. In order to achieve this, four case studies were investigated and the results for both passive and active variable acoustics were evaluated to understand the performance results. The variable acoustics methods was then applied to Paul H. Cocker Gallery.

After evaluating the measurements that were done in in Roy Thomson Hall, Koerner Hall, and Glen Gould Studio, which were the auditoria that all used passive variable acoustics, it can be concluded that passive acoustical techniques can provide range of different reverberartion times for different uses. The changes in reverberation time in these auditoria were assessed for different conditions. Also, the passive variable acoustics impacts were tested in the Paul Cocker Gallery in order to evaluate if using this method is beneficial to improve the Gallery's acoustics. Also, measurements were done LIVELab at McMaster University which uses active variable acoustics to control the acoustics of the room.

By investigating the case studies and using the on-site measurements along with the computer simulation, the use of the acoustic boards in order to change the acoustical response of the Gallery is validated. It was concluded that using six poster board panels in the Gallery can make the room suitable for presentations and classroom setting. Also, if possible, adding eight poster board panels to the room in total, can be a better setting for classroom. Since the acoustic panels are portable, they can be easily removed or added to Gallery. Also, attaching acoustical panels on the walls are another solution for using gallery for classroom and presentations. However, the acoustical panels are not removable and will take the wall space which is used for 
attaching posters in the Gallery. Therefore, the four major uses of the Gallery space which were exhibitions, crit space, presentation with the use of speakers and LCD, and a small chamber music with 30 seats and 4 musicians, are achievable using poster board panels in the Gallery.

The measurements were done in the LiveLab located at McMaster University and results show that more ranges of variability can be done using the active variable acoustics systems. However, this method can only add reverberation and cannot reduce it. Therefore, in order to use this method in Gallery, first the reverberation time in that space should be refined to become as short as possible meaning less than 0.5 seconds. In order to test if this is a possibility, twelve poser panels were introduced to the room and simulated. The results show that room's reverberation time became close to 0.5 seconds. However, adding this many poster board panels can make the room look smaller and crowded.

Further, active acoustics systems tend to be very expensive. The system that is used in the LIVELab cost about one million dollars. This means that if the same method is used the Gallery, based on its size, around twenty microphones and seventy speakers are needed. The same amount of one million dollars is expected to be cost of the system to be employed in the Gallery. Therefore, it will be more feasible for the Gallery to use passive acoustics methods rather than the active acoustics since the passive changes to the room proven effective for different uses of the room.

From the findings of this research, it can be concluded that adding absorptive material to a room decreases the reverberation time. Active acoustics control of a room is an effective and easy way to change the functions of a room, however, it tend to be an expensive method and hard to achieve in a highly reverberant space. 


\section{Appendices}

\section{Appendix A: Roy Thomson Hall Measurement Results}
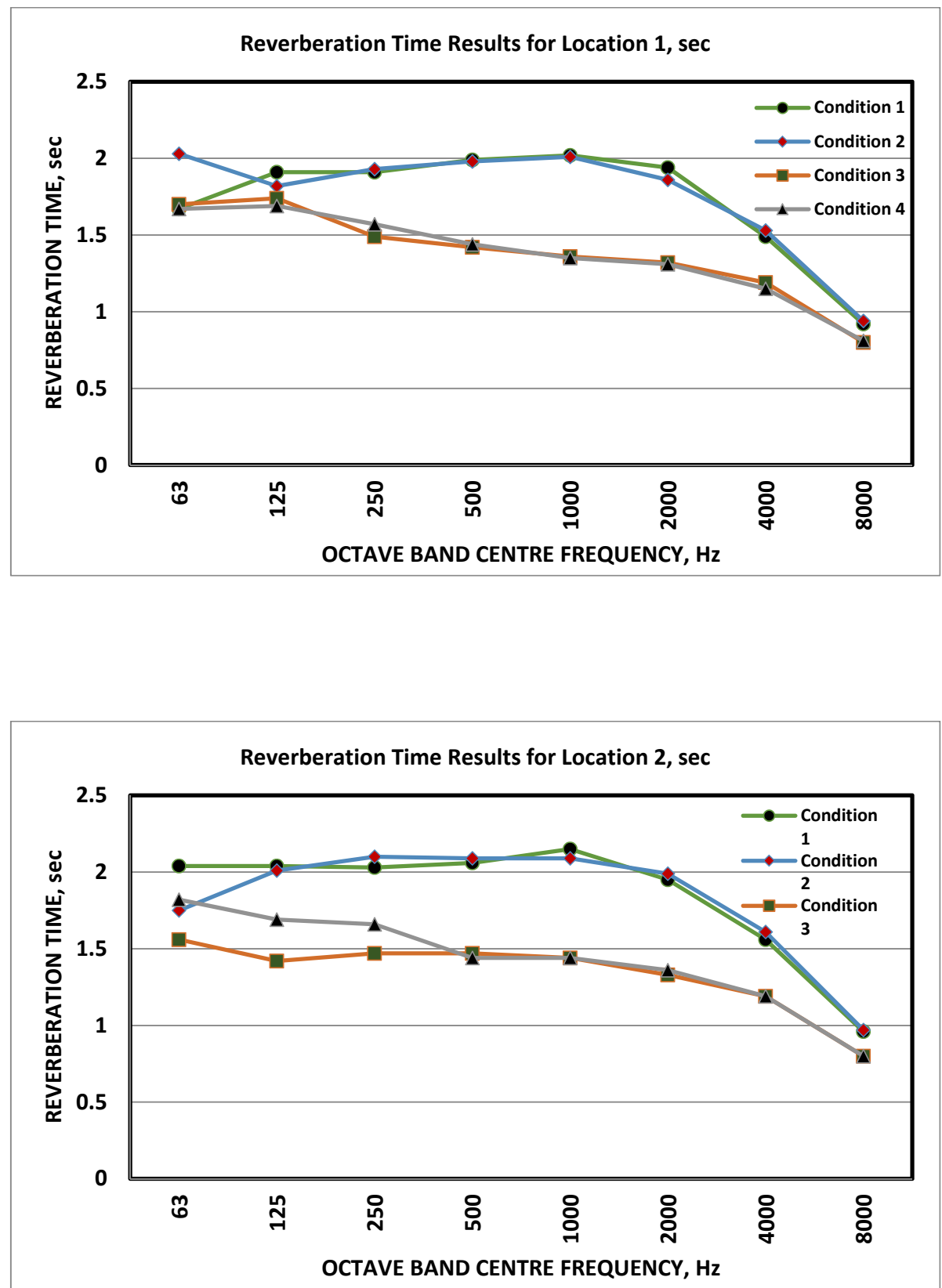

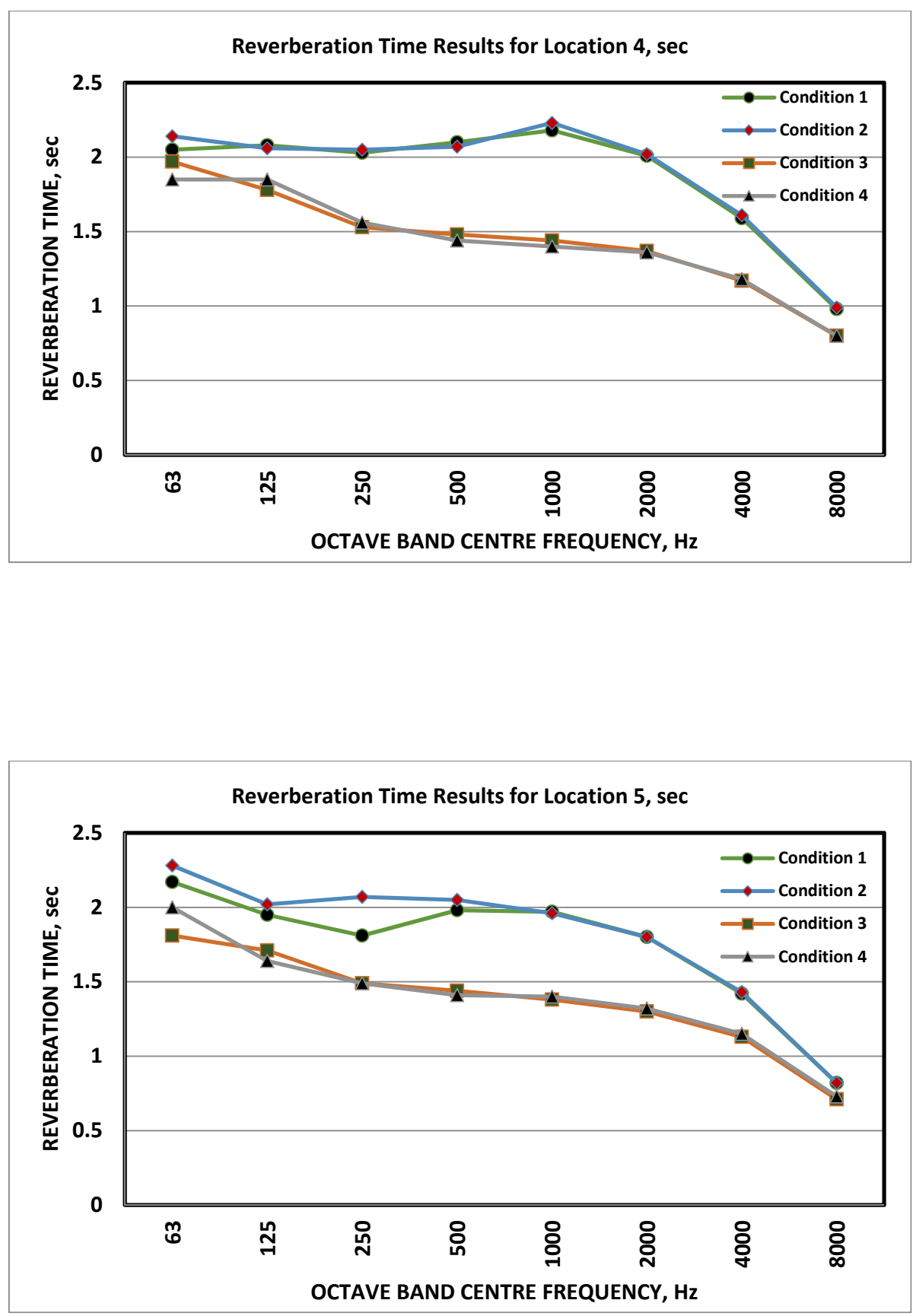

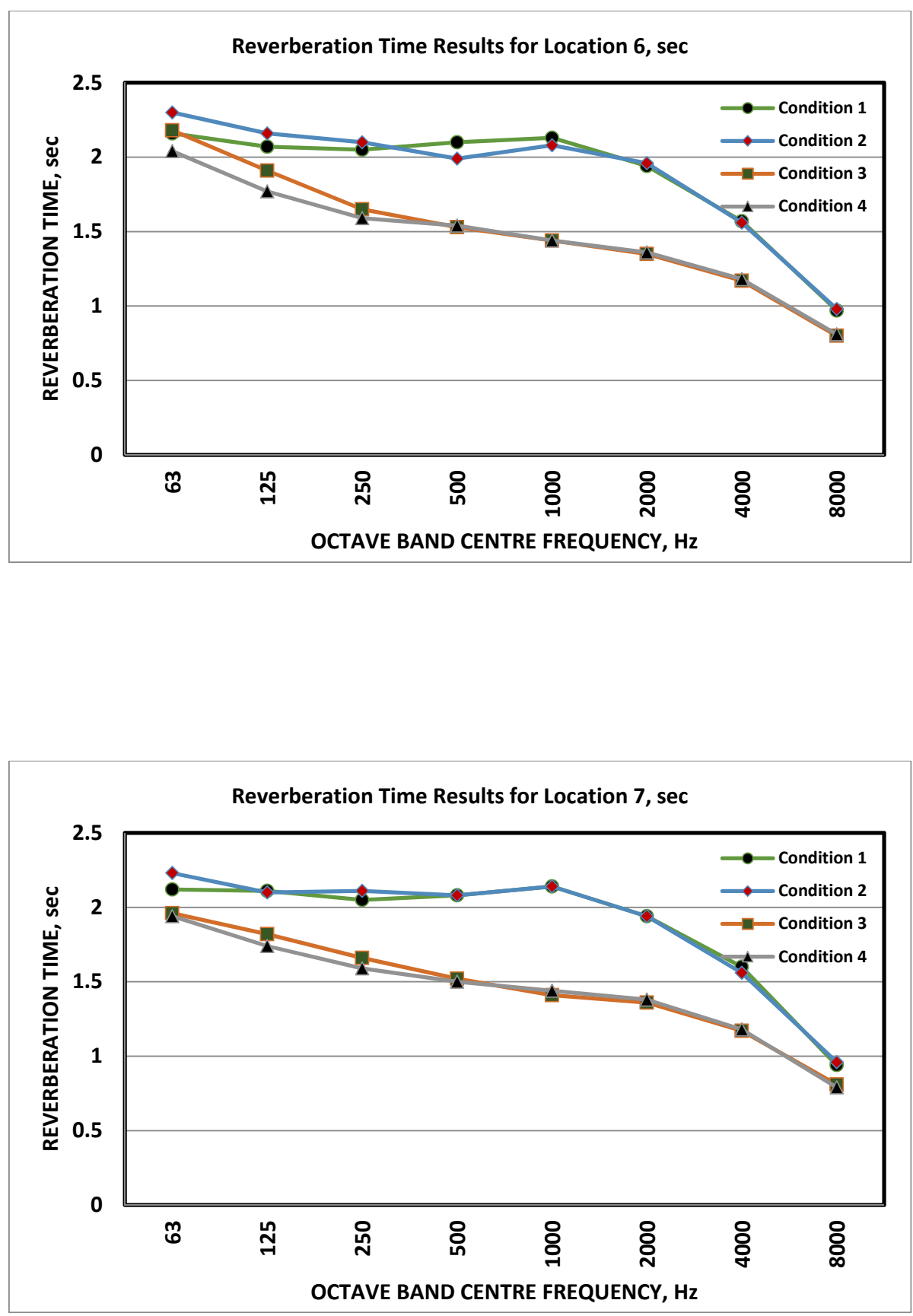


\section{Appendix B: Koerner Hall Measurement Results}
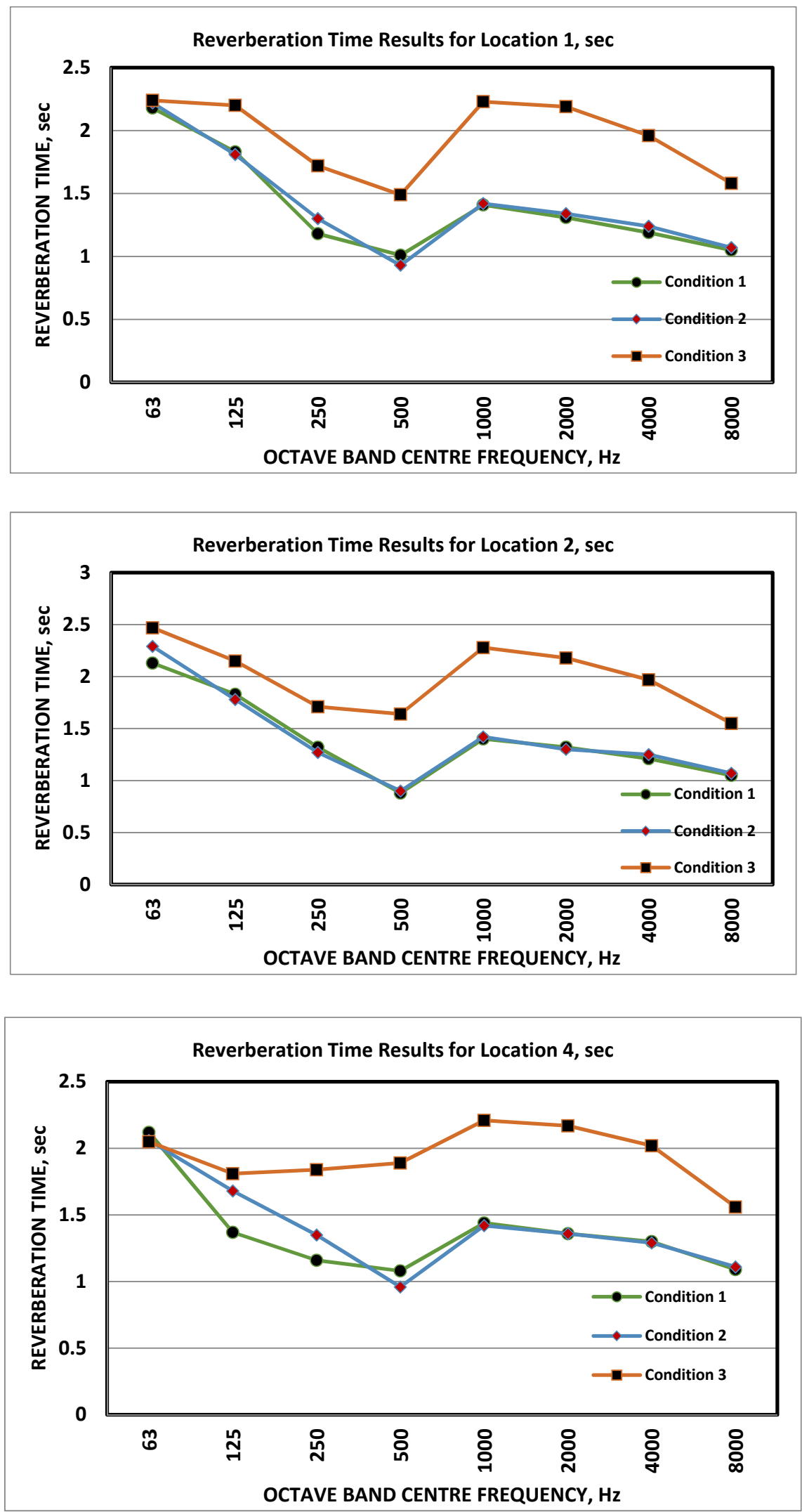


\section{Appendix C: Glenn Gould Studio Measurement Results}
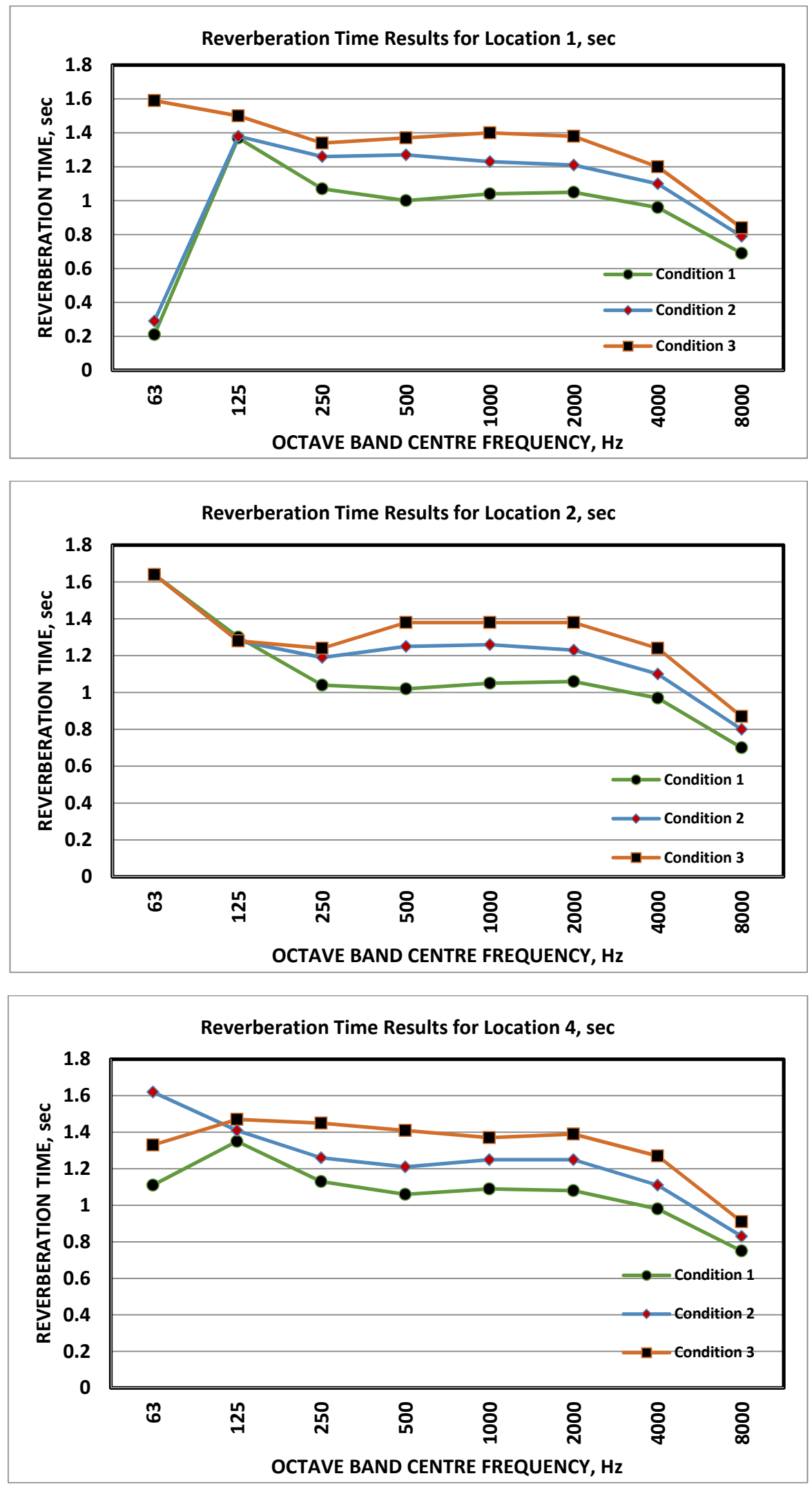
Appendix D: LIVELab Measurement Results

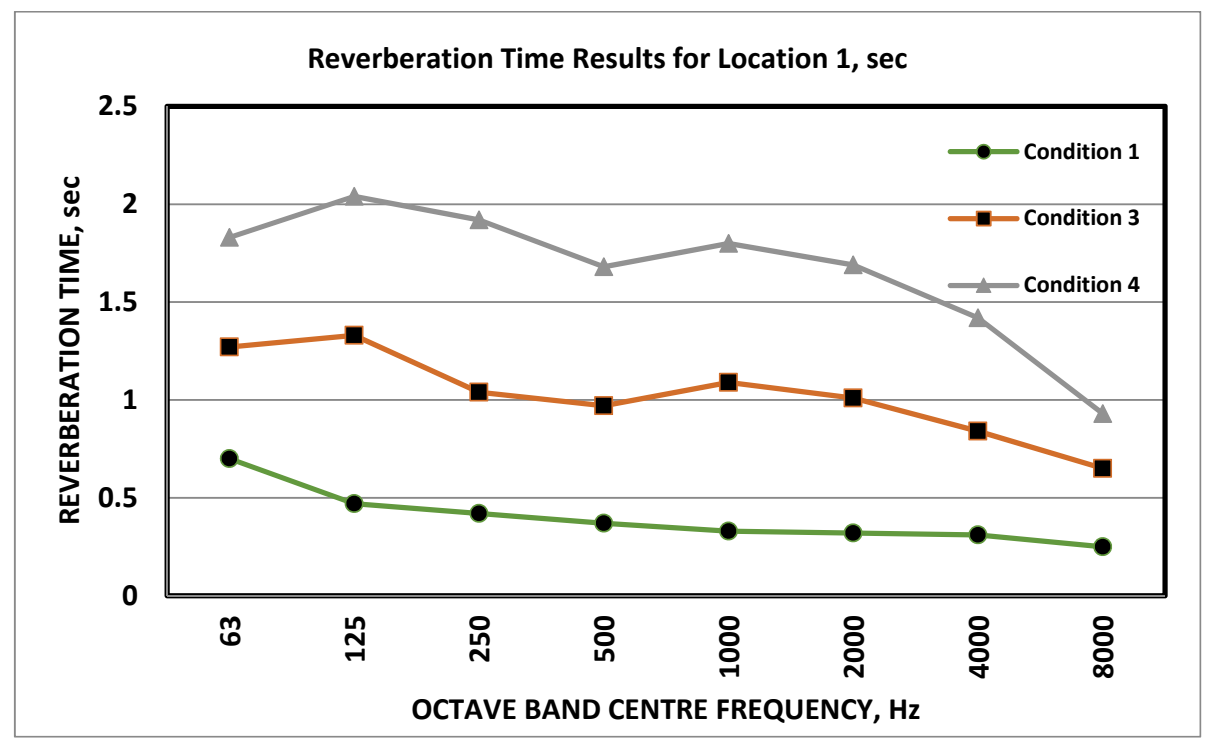




\section{References}

1. Diemer de Vries, "Variable Acoustics in Auditoria yesterday, today and tomorrow," Proceedings of International Commission for Acoustics, Laboratory of Acoustical Imaging and Sound Control, Department of Applied Physics, Delft University of Technology (2001).

2. E. A. Wetherill, "Variable acoustics: A review of several auditoria," The Journal of the Acoustical Society of America, Vol. 69, S 74 (1981).

3. M. Cairoli, "Architectural customized design for variable acoustics in a Multipurpose Auditorium," Journal of Applied Acoustics, Vol. 140, pp 167-177 (2018).

4. M. Long, “Architectural Acoustics,” 2nd Ed., Academic Press, pp 697 (2014).

5. M. Barron . S. Kissner "A possible acoustic approach for multi-purpose auditoria suitable for both speech and music,” Applied Acoustics, Vol. 115, pp. $42-49$ (2017).

6. J.C. Jaffe., "The Acoustics of Performance Halls,” W.W. Norton and Company, pp.99 (2010).

7. M. A. Poletti, "Active Acoustic Systems for the Control of Room Acoustics," Proceedings of the International Symposium on Room Acoustics, pp. 29-31 (2010).

8. R. Schwenke, S. Ellison. "Objective Assessment of Active Acoustic System Performance," Proceedings of the International Symposium on Room Acoustics, pp. 29-31 (2010).

9. S. Ellison, R. Schwenke "The Case for Widely Variable Acoustics," Proceedings of the International Symposium on Room Acoustics, pp. 29-31 (2010).

10. Colorado College, Online, Retrieved from https://www.uniquevenues.com/coloradocollege 
11. R. Schwenke, S. Ellison. "Active Acoustics in Physically Variable Spaces," International Symposium on Room Acoustics, (2013).

12. R. Schwenke, "Active acoustics and sound reinforcement at TUI Operettenhaus, Hamburg: A case study," Proceedings of Meetings on Acoustics, International Congress of Acoustics, Vol.13 (2013).

13. R. Ramakrishnan, Course Notes, “Advanced Acoustical Design,” (2018).

14. The Speech Transmission Index, "Embedded Acoustics," Online, Retrieved From https://www.embeddedacoustics.com/index.php/speech-transmission-index

15. A. Farina, "Aurora Plugins," Retrieved From https://auroraplugins.forumfree.it/?t=53443032

16. Odeon Room Acoustics Software, Online, Retrieved From https://odeon.dk/acoustics_simulation_software/specifications

17. E. Johnston-Iafelice, "Impact of Curved Surfaces in Performance Spaces", Major Research Paper, Department of Architectural Science, Ryerson university (May 2018) 